Illinois State University

ISU ReD: Research and eData

Theses and Dissertations

$10-9-2017$

\title{
Physical Activity and Associated Energy Intake in Undergraduate College Students
}

\author{
Erin Marie Fejes \\ Illinois State University, efejes@hotmail.com
}

Follow this and additional works at: https://ir.library.illinoisstate.edu/etd

Part of the Human and Clinical Nutrition Commons

\section{Recommended Citation}

Fejes, Erin Marie, "Physical Activity and Associated Energy Intake in Undergraduate College Students" (2017). Theses and Dissertations. 855.

https://ir.library.illinoisstate.edu/etd/855

This Thesis is brought to you for free and open access by ISU ReD: Research and eData. It has been accepted for inclusion in Theses and Dissertations by an authorized administrator of ISU ReD: Research and eData. For more information, please contact ISUReD@ilstu.edu. 


\title{
PHYSICAL ACTIVITY AND ASSOCIATED ENERGY INTAKE IN UNDERGRADUATE COLLEGE STUDENTS
}

\author{
Erin Marie Fejes
}

\section{Pages}

Background: College students often develop unhealthy eating habits. Poor eating habits can lead to chronic disease.

Methods: Energy intake and physical activity data from 35 undergraduate students enrolled in a 100-level kinesiology class were recorded and analyzed. Energy intake data was self-reported, while physical activity data was recorded via an activity tracker.

Results: Data points were analyzed twice: each day separately and as averages for each participant. When analyzed as averages, grams of total fat and grams of carbohydrate were the most significantly correlated with minutes of moderate to vigorous+ physical activity (both $\mathrm{p}<0.01$ ). When analyzed by day, grams of protein, total fat, saturated fat, carbohydrate, sugar, and fiber were all found to be significantly correlated with minutes of moderate to vigorous physical activity to the $\mathrm{p} \leq 0.01$ level.

Conclusion: An increase in physical activity is associated with a greater increase in the consumption of carbohydrates and total fat than protein. Future studies should seek to investigate the difference in the increase of carbohydrate and total fat versus protein and whether participants consume the same foods when they participate in increased physical activity as they do when they engage in lower intensity physical activity. 
KEYWORDS: Energy Intake, Physical Activity, Exercise, Undergraduate College Student 
PHYSICAL ACTIVITY AND ASSOCIATED ENERGY INTAKE IN UNDERGRADUATE

COLLEGE STUDENTS

\author{
ERIN MARIE FEJES
}

A Thesis Submitted in Partial Fulfillment of the Requirements for the Degree of

MASTER OF SCIENCE

Department of Family and Consumer Sciences

ILLINOIS STATE UNIVERSITY

2018 
(C) 2018 Erin Marie Fejes 
PHYSICAL ACTIVITY AND ASSOCIATED ENERGY INTAKE IN UNDERGRADUATE

COLLEGE STUDENTS

\author{
ERIN MARIE FEJES
}

COMMITTEE MEMBERS:

Jennifer L. Barnes, Chair

Dale D. Brown

Karen K. Dennis

Julie M. Schumacher 


\section{ACKNOWLEDGMENTS}

I would like to thank my committee members Dale Brown, Karen Dennis, and Julie Schumacher for their help with the activity trackers and the editing process of this thesis. A special thanks goes to my thesis chair, Jennifer Barnes, for providing the initial idea for this topic and helping me throughout the entire process by giving suggestions, edits, and encouragement. Finally, I would like to thank my parents, Robert and Diane Fejes, for their endless support throughout my graduate school endeavors, and my sister, Anna Fejes, for helping to edit the final draft.

E. M. F. 


\section{CONTENTS}

Page

ACKNOWLEDGMENTS

$\begin{array}{ll}\text { CONTENTS } & \text { ii }\end{array}$

TABLES $\quad$ iv

FIGURES

CHAPTER I: PHYSICAL ACTIVITY AND ASSOCIATED ENERGY INTAKE IN

UNDERGRADUATE COLLEGE STUDENTS 1

Introduction 1

$\begin{array}{ll}\text { Methodology } & 4\end{array}$

$\begin{array}{ll}\text { Participants } & 4\end{array}$

Instruments/Measurements $\quad 4$

Data Analysis $\quad 6$

$\begin{array}{ll}\text { Results } & 7\end{array}$

Data Analysis of Averages of 35 Participants $\quad 7$

Data Analysis of All Daily Diet and Physical Activity Pairs 9

$\begin{array}{ll}\text { Discussion } & 23\end{array}$

CHAPTER II: EXTENDED LITERATURE REVIEW 29

Energy Intake in College Students $\quad 29$

Physical Activity in College Students 33

Energy Intake and Physical Activity in College Students 36

Empty Calorie Intake and Physical Activity in College Students 37

Saturated Fat Intake in College Students $\quad 39$ 
Sugar Intake in College Students $\quad 40$

$\begin{array}{ll}\text { Energy Balance } & 41\end{array}$

$\begin{array}{ll}\text { Activity Tracker } & 42\end{array}$

$\begin{array}{ll}\text { REFERENCES } & 44\end{array}$

APPENDIX A: DIETARY RECALL AND ACTIVITY LOG INSTRUCTIONS 52

APPENDIX B: DIETARY RECALL AND ACTIVITY LOG TEMPLATE 54 


\section{TABLES}

Table

Page

1. Demographics 11

2. Averages and Standard Deviations (SD) for All Variables 12

3. Significant Variables for Moderate to Vigorous+ Physical Activity for 35

Participants

4. Non-Significant Variables for Moderate to Vigorous+ Physical Activity for 35

Participants

5. Significant Variables for Moderate to Vigorous+ Physical Activity for All Daily

Diet and Physical Activity Pairs

6. Non-Significant Variables for Moderate to Vigorous+ Physical Activity for All Daily

Diet and Physical Activity Pairs 


\section{FIGURES}

Figure

Page

1. Energy expenditure vs. minutes of moderate to vigorous + physical activity

2. Energy intake vs. minutes of moderate to vigorous+ physical activity

3. Grams of fat vs. minutes of moderate to vigorous+ physical activity

4. Grams of saturated fat vs. minutes of moderate to vigorous+ physical activity

5. Grams of carbohydrate vs. minutes of moderate to vigorous+ physical activity

6. Calories expended vs. minutes of moderate to vigorous+ physical activity

7. Kilocalories per kilogram of body weight vs. minutes of moderate to vigorous+ physical activity

8. Grams of protein per kilogram of bodyweight vs. minutes of moderate to vigorous + physical activity

9. Grams of fat vs. minutes of moderate to vigorous+ physical activity

10. Grams of saturated fat vs. minutes of moderate to vigorous+ physical activity

11. Grams of carbohydrate vs. minutes of moderate to vigorous+ physical activity

12. Energy intake vs. minutes of moderate to vigorous+ physical activity

13. Grams of protein vs. minutes of moderate to vigorous+ physical activity

14. Grams of sugar vs. minutes of moderate to vigorous+ physical activity

15. Grams of fiber vs. minutes of moderate to vigorous+ physical activity 


\section{CHAPTER I: PHYSICAL ACTIVITY AND ASSOCIATED ENERGY INTAKE IN UNDERGRADUATE COLLEGE STUDENTS}

\section{Introduction}

Unhealthy eating habits are often found within the college student population (Gorgulho et al., 2012; Quick \& Byrd-Bredbenner, 2013; Seward, Block, \& Chatterjee, 2016; SmithJackson \& Reel, 2012). Unhealthy eating behaviors can cause students to gain weight and become overweight or obese (Smith-Jackson \& Reel, 2012) which then may lead to greater, potentially chronic, health problems in the future (Morrell, Lofgren, Burke, \& Reilly, 2012). Healthy eating is therefore associated with lower rates of chronic diseases.

Just as eating healthy can ward off disease, participation in regular physical activity can have a positive impact on a person's physical health (Warburton, Charlesworth, Ivey, Nettlefold, \& Bredin, 2010). Regular physical activity has been well-documented in its ability to fend off many health problems including cardiovascular disease, diabetes, and high blood pressure (Sundblad, Jansson, Saartok, Renström, \& Engström, 2008; Waxman, n.d.). Physical activity is defined as any bodily movement that requires the use of muscles and expends more energy than resting ("What Is Physical Activity? - NHLBI, NIH," n.d.).

Current recommendations for physical activity vary by age group. Children and adolescents who are 6-17 years of age should participate in 60 minutes or more of physical activity each day ("Physical Activity Basics | Physical Activity | CDC," 2017). Much of this 60minute time block should consist of moderate to vigorous physical activity. In addition, children and adolescents should participate in both muscle strengthening and bone strengthening exercises three or more times each week ("Physical Activity Basics | Physical Activity | CDC," n.d.). Adults between 18-64 years of age are recommended to participate in either 150 minutes 
of moderate aerobic physical activity each week, 75 minutes of vigorous aerobic physical activity each week, or an equivalent combination of moderate and vigorous aerobic physical activity ("Physical Activity Basics | Physical Activity | CDC," 2017). Adults are also advised to participate in muscle strengthening activities two or more days per week for each of the major muscle groups (legs, hips, back, abdomen, chest, shoulders, and arms) ("Physical Activity Basics | Physical Activity | CDC,” 2017).

Several studies have looked at energy expenditure and subsequent energy intake in various groups of people. Energy intake is defined as the energy obtained from the food and drink that is consumed by a person ("Energy intake and expenditure - British Nutrition Foundation," n.d.). One study looking at middle school and high school students who engaged in intense physical activity found that this type of activity did not lead to an increase in the consumption of unhealthy foods afterwards (Durksen et al., 2015). However, another study by Fayet, Flood, Petocz, \& Samman (2014), found that female college student participants who engaged in moderate physical activity consumed an extra two servings of food each day, mostly in the form of empty calories. Empty calories are defined as calories from foods which do not contain or have very few nutrients, such as fiber, vitamins, and minerals ("Obesity Action Coalition » Empty Calories: Do they add up?,” n.d.). Another study determined that total energy intake did not increase in young adults with a mean age of 28.2 years, who walked over 2,000 extra steps a day (Koulouri, Tigbe, \& Lean, 2006).

These studies show conflicting results, limitations, and gaps which allow for the formation of the current study. Research by Fayet et al. (2014) studied solely females, while the study by Koulouri et al. (2006) contained only 12 participants. The study by Durksen et al. (2015) looked at middle school and high school students, whereas the proposed study was 
interested in the behavior of college students. Therefore, it was appropriate to conduct a study that looked at a large sample size of male and female college students, their physical activity habits, and subsequent energy intake.

The purpose of this survey study was to examine the correlation between physical activity and subsequent food and beverage consumption in college students enrolled in a 100level undergraduate kinesiology class focused on overall health and the development of a personalized fitness program.

Within this study, two hypotheses were tested:

1) A greater amount of time spent engaging in moderate to vigorous+ physical activity will be associated with a greater kilocalorie intake in college students.

2) A greater amount of time spent engaging in moderate to vigorous+ physical activity will be associated with greater consumption of sugar and saturated fat in college students.

For both hypotheses, the independent variable was physical activity and the dependent variables were energy intake and sugar and saturated fat intake.

This study allows researchers to better understand college students' physical activity and energy intake patterns which, in turn, enables nutrition educators to understand more fully which areas need to be addressed with regard to college students and their health. This study revealed the associations between physical activity and energy intake in young adults approximately 1822 years old. 


\section{Methodology}

\section{Participants}

A total of 105 students were recruited to participate in this study via a convenience sample through an undergraduate kinesiology class entitled Personal Fitness. This class is a 100level course open to both females and males interested in physical fitness and/or nutrition. Three sections of this class were held during the spring 2017 semester; two in-person sections and one online section. The first in-person class had 29 students enrolled, while the second in-person class and the online class both had 38 students enrolled. Out of the 105 total students enrolled in this class, data from 35 students was ultimately analyzed and included in this study. Data was collected from consenting individuals during the spring semester of 2017. All students enrolled in this course were approached in person for participation. All students were informed that participation was voluntary and that it would not impact their course grade in any way. Students were informed they would not have to do anything outside of course requirements for data collection; all data measures were already part of their course requirements and students who consented to participate simply allowed researchers to access their data. Human subjects approval was granted by the Illinois State University Institute Review Board before any data was collected.

\section{Instruments/Measurements}

Participant data was collected via 1) an activity tracker and 2) a diet and activity log. The particular activity tracker used for this study was the Polar Active watch (WR 30m, CR2025). This watch was individualized for accuracy using each participant's height, weight, gender, and age. Participants were instructed to wear the watch on their non-dominant hand 24 hours/day for seven consecutive days. Data collected from the Polar Active watch included total daily energy 
expenditure (in kilocalories), total daily steps taken, level of physical activity (very easy, easy, moderate, vigorous, or vigorous+), and duration of time spent at each level of physical activity. The Polar Active watch records the frequency, intensity and regularity of wrist movement. This information is then calculated and assigned one of the corresponding activity levels listed above.

The method of recording dietary intake included asking the participant to record all foods, including snacks and beverages, consumed during a specified time period ("UCLA Nutrition Education," n.d.). For this study, the diet and activity log was conducted over the period of seven consecutive days that participants wore the Polar Active watch. This log provided each participant's energy intake and physical activity data for each day during that time period. Due to many participants having incomplete data for the seven days, this study reviews five days of data from each participant (one participant with four days of data was also included). Each participant's data included at least one weekend day. The diet and activity log used for this study asked participants to record the date, time, food/beverage consumed, the brand of the food/beverage (if applicable), the method used to prepare the food, and the amount of the food/beverage consumed. Participants were asked to be as specific as possible when recording food and beverage intake, and they were encouraged to use measuring spoons and cups to measure the amount of food or beverage being consumed.

The activity section of the diet and activity log asked participants to record the date, start time, general activity type, and the duration of physical activity. Although the participants wore the Polar Active watch to track physical activity, the data from this watch does not inform researchers what time of day the participants engaged in physical activity. For this reason, participants were also asked to complete the activity section of the diet and activity log. Diet and 
activity $\log$ s were recorded by participants on a provided paper template. See Appendix B for a sample diet and activity $\log$.

\section{Data Analysis}

The data collected as part of the diet and activity log was self-reported by participants. As part of the kinesiology class the participants were enrolled in, students entered their dietary information into the NutriCalc Plus computer software program. The data of consenting participants was made available to researchers who were then able to compile this data for further analysis. Activity tracker data included calories expended, steps taken, and the intensity and duration of physical activity. This data was gathered from Polargofit.com after each Polar Active watch was synced to transfer data from the watch to a computer. Descriptive statistics were conducted for age, gender, and BMI. Pearson correlations were employed to detect associations between physical activity and total energy expenditure, total energy intake, kilocalories per kilogram of bodyweight, total grams of protein, grams of protein per kilogram of bodyweight, grams of fat, grams of saturated fat, percent of total kilocalories from saturated fat, grams of trans fat, grams of carbohydrate, grams of sugar, percent of total kilocalories from sugar, and grams of fiber. Corresponding scatter plots were created for each dietary variable. The collected data was analyzed in two ways: by using the average of each participants' data to get one number for each data point, and by analyzing each day of each participant as a separate data point, yielding 174 data points (34 participants had five days of data, while one participant had four days of data), rather than 35 participants. Analyzing the data twice, once as an average for each of the 35 participants and again as individual participants for each day of recorded energy intake and physical activity, allowed researchers to view an average change in nutrient intake over the five-day record as well as day-to-day changes in nutrient intake. All data was considered 
statistically significant when $\mathrm{p}<0.05$. All statistical analyses were conducted via IBM SPSS Statistics software version 22.

\section{Results}

Out of 105 students, 85 students elected to participate in this study by signing the informed consent. Of these, 12 participants did not turn in either a hard copy diet and activity log nor an electronic copy uploaded to the NutriCalc Plus computer software, four participants had less than four days of dietary data available, four participants' diet log dates and activity tracker dates did not match, five participants had less than three days of activity tracker data and/or did not include a weekend day, and 25 participants were not specific enough when recording their diet and thus researchers could not accurately enter these diets into the NutriCalc Plus computer software. These exclusions resulted in a total of 35 participants whose data was found to be complete and appropriate for use in this study. Thirty-four of these participants had five days of diet and activity data for analysis, while one participant had four days of diet and activity data for analysis. Each participant's data included at least one weekend day. Out of the 35 participants, $71.4 \%$ were female $(n=25)$, while $28.6 \%$ were male $(n=10)$. The mean BMI was 25.19 , and the mean age was 21.27 (Table 1).

\section{Data Analysis of Averages of 35 Participants}

The five dietary variables that yielded significant results when correlated with minutes of moderate to vigorous+ physical activity were daily energy expenditure (in kilocalories), energy intake (in kilocalories), grams of total fat, grams of saturated fat, and grams of carbohydrate.

There was a significant positive relationship between energy expenditure and minutes of moderate to vigorous+ physical activity, $\mathrm{r}=0.754, \mathrm{p}<0.01$. Energy intake and minutes of moderate to vigorous+ physical activity were also found to have a significant positive 
relationship, $\mathrm{r}=0.552, \mathrm{p}<0.01$. There was a significant positive relationship between grams of total fat and minutes of moderate to vigorous+ physical activity, $\mathrm{r}=0.589, \mathrm{p}<0.01$. The relationship between grams of saturated fat and minutes of moderate to vigorous+ physical activity was also found to be significantly positive, $r=0.412, p<0.05$. Finally, a significant positive relationship was found between grams of carbohydrate and minutes of moderate to vigorous+ physical activity, $\mathrm{r}=0.438, \mathrm{p}<0.01$.

There were nine variables that were not significantly correlated with minutes of moderate to vigorous+ physical activity. These variables were BMI, kilocalories per kilogram of bodyweight, grams of protein, grams of protein per kilogram of bodyweight, percent of total kilocalories from sugar, grams of sugar, grams of fiber, grams of trans fat, and percent of total kilocalories from saturated fat. There was no significant relationship between BMI and minutes of moderate to vigorous+ physical activity, $r=0.114, p>0.05$. Kilocalories per kilogram of bodyweight and minutes of moderate to vigorous+ physical activity were not found to have a significant relationship, $r=0.321, p>0.05$. However, there was a trend towards significance for this variable as $p=0.06$. While there was no significant relationship between grams of protein and minutes of moderate to vigorous+ physical activity, $r=0.286, p>0.05$, there was also a trend towards significance for this variable as $\mathrm{p}=0.096$. There was no significant relationship between grams of protein per kilogram of bodyweight and minutes of moderate to vigorous+ physical activity, $\mathrm{r}=0.193, \mathrm{p}>0.05$. No significant relationship was found between percent of total kilocalories from sugar and minutes of moderate to vigorous + physical activity, $r=0.036, p$ $>0.05$. While there was no significant relationship between grams of sugar and minutes of moderate to vigorous+ physical activity, $\mathrm{r}=0.323, \mathrm{p}>0.05$, there was a trend towards significance with a p-value of 0.058 . There was no significant relationship between grams of 
fiber and minutes of moderate to vigorous + physical activity, $r=0.243, p>0.05$. No significant relationship was found between grams of trans fat and minutes of moderate to vigorous+ physical activity, $r=0.099, \mathrm{p}>0.05$. Finally, there was no significant relationship between percent of total kilocalories from saturated fat and minutes of moderate to vigorous+ physical activity, $\mathrm{r}=0.078, \mathrm{p}>0.05$.

\section{Data Analysis of All Daily Diet and Physical Activity Pairs}

The ten dietary variables which yielded significant results when correlated with minutes of moderate to vigorous+ physical activity were energy expenditure (in kilocalories), kilocalories per kilogram of bodyweight, energy intake (in kilocalories), grams of protein, grams of protein per kilogram of bodyweight, grams of total fat, grams of saturated fat, grams of carbohydrate, grams of sugar, and grams of fiber. All five dietary variables that were significant after analyzing the data as 35 participants were also significant when analyzing each day of data for each participant as a separate data point, thus yielding 174 separate data points, which will be referred to as "all daily diet and physical activity pairs" from this point forward.

There was a significant positive relationship between energy expenditure and minutes of moderate to vigorous+ physical activity, $\mathrm{r}=0.744, \mathrm{p}<0.01$. Kilocalories per kilogram of bodyweight and minutes of moderate to vigorous+ physical activity were found to have a significant positive relationship, $\mathrm{r}=0.229, \mathrm{p}<0.01$. A significant positive relationship was found between energy intake and minutes of moderate to vigorous+ physical activity, $\mathrm{r}=0.392$, $\mathrm{p}<0.01$. There was a significant positive relationship between grams of protein and minutes of moderate to vigorous+ physical activity, $\mathrm{r}=0.235, \mathrm{p}<0.01$. Grams of protein per kilogram of bodyweight and minutes of moderate to vigorous+ physical activity were found to have a significant positive relationship, $\mathrm{r}=0.175, \mathrm{p}<0.05$. There was a significant positive relationship 
between grams of fat and minutes of moderate to vigorous + physical activity, $r=0.364, p<0.01$. A significant positive relationship was found between grams of saturated fat and minutes of moderate to vigorous + physical activity, $r=0.274, p<0.01$. There was a significant positive relationship between grams of carbohydrate and minutes of moderate to vigorous+ physical activity, $\mathrm{r}=0.294, \mathrm{p}<0.01$. Grams of sugar and minutes of moderate to vigorous + physical activity were found to have a significant positive relationship, $r=0.268, \mathrm{p}<0.01$. And finally, a significant positive relationship was found between grams of fiber and minutes of moderate to vigorous+ physical activity, $\mathrm{r}=0.167, \mathrm{p}<0.01$.

There were four variables that were not significant when compared with moderate to vigorous+ physical activity. These variables were BMI, percent of total kilocalories from sugar, grams of trans fat, and percent of total kilocalories from saturated fat. There was no significant relationship between BMI and moderate to vigorous+ physical activity, $r=0.099, p>0.05$. No significant relationship was found between percent of total kilocalories from sugar and moderate to vigorous + physical activity, $\mathrm{r}=0.035, \mathrm{p}>0.05$. Grams of trans fat and moderate to vigorous+ physical activity were not found to have a significant relationship, $r=0.015, p>0.05$. No significant relationship was found between percent of total kilocalories from saturated fat and moderate to vigorous+ physical activity, $\mathrm{r}=0.079, \mathrm{p}>0.05$. 
Table 1. Demographics

\begin{tabular}{|c|c|c|c|c|}
\hline Variable & & $\mathrm{N}=35$ & Range & Mean \pm SD \\
\hline BMI & & & $18-35$ & $25.18 \pm 4.4$ \\
\hline Age & & & $19-24$ & $21.27 \pm 1.17$ \\
\hline Variable & & $\mathbf{N}$ & & Percent \\
\hline \multicolumn{5}{|l|}{ Gender } \\
\hline & Female & 25 & & 71.4 \\
\hline & Male & 10 & & 28.6 \\
\hline & Total & 35 & & 100.0 \\
\hline
\end{tabular}


Table 2. Averages and Standard Deviations (SD) for All Variables

\begin{tabular}{|c|c|}
\hline Variable & Average $( \pm$ SD) \\
\hline Calories Expended & $2,691 \pm 821$ \\
\hline Energy Intake (kilocalories) & $1,678 \pm 596$ \\
\hline Protein (grams) & $82 \pm 45$ \\
\hline Fat (grams) & $60 \pm 31$ \\
\hline Saturated Fat (grams) & $19 \pm 13$ \\
\hline Carbohydrate (grams) & $203 \pm 82$ \\
\hline Sugar (grams) & $72 \pm 44$ \\
\hline Fiber (grams) & $17 \pm 8$ \\
\hline Grams of Fiber per 1,000 kilocalories & $11 \pm 5$ \\
\hline Trans Fat (grams) & $1 \pm 1$ \\
\hline Minutes of Very Easy Physical Activity for 1 day & $636 \pm 182$ \\
\hline Minutes of Easy Physical Activity for 1 day & $261 \pm 113$ \\
\hline Minutes of Moderate Physical Activity for 1 day & $57 \pm 40$ \\
\hline Minutes of Vigorous Physical Activity for 1 day & $14 \pm 18$ \\
\hline Minutes of Vigorous+ Physical Activity for 1 day & $4 \pm 8$ \\
\hline Minutes of Very Easy to Easy Physical Activity for 1 day & $896 \pm 185$ \\
\hline Minutes of Moderate to Vigorous+ Physical Activity for 1 day & $75 \pm 60$ \\
\hline Daily Steps & $15,024 \pm 8,109$ \\
\hline
\end{tabular}


Table 3. Significant Variables for Moderate to Vigorous+ Physical Activity for 35 Participants

\begin{tabular}{lcc}
\hline Variable & R Value & P Value \\
\hline Energy expenditure & 0.754 & 0.000 \\
Energy intake & 0.552 & 0.001 \\
Grams of total fat & 0.589 & 0.000 \\
Grams of saturated fat & 0.412 & 0.014 \\
Grams of carbohydrate & 0.438 & 0.008 \\
\hline
\end{tabular}

Table 4. Non-Significant Variables for Moderate to Vigorous+ Physical Activity for 35 Participants

\begin{tabular}{lcc}
\hline Variable & R Value & P Value \\
\hline BMI & 0.114 & 0.514 \\
Kilocalories per kilogram of bodyweight & 0.321 & 0.060 \\
Grams of protein & 0.286 & 0.096 \\
Grams of protein per kilogram of bodyweight & 0.193 & 0.266 \\
Percent of total kilocalories from sugar & -0.036 & 0.839 \\
Grams of sugar & 0.323 & 0.058 \\
Grams of fiber & 0.243 & 0.159 \\
Grams of trans fat & 0.099 & 0.573 \\
Percent of total kilocalories from saturated fat & 0.078 & 0.658 \\
\hline
\end{tabular}


Table 5. Significant Variables for Moderate to Vigorous+ Physical Activity for All Daily Diet and Physical Activity Pairs

\begin{tabular}{llc}
\hline Variable & R Value & P Value \\
\hline Energy expenditure & 0.744 & 0.000 \\
Energy intake & 0.392 & 0.000 \\
Gram of fat & 0.364 & 0.000 \\
Grams of saturated fat & 0.274 & 0.000 \\
Grams of carbohydrate & 0.294 & 0.000 \\
Kilocalories per kilogram of body weight & 0.229 & 0.002 \\
Grams of protein per kilogram of body weight & 0.175 & 0.021 \\
Grams of protein & 0.235 & 0.002 \\
Grams of sugar & 0.268 & 0.000 \\
Grams of fiber & 0.167 & 0.027
\end{tabular}

Table 6. Non-Significant Variables for Moderate to Vigorous+ Physical Activity for All Daily Diet and Physical Activity Pairs

\begin{tabular}{lcc}
\hline Variable & R Value & P Value \\
\hline BMI & 0.099 & 0.192 \\
Percent of total kilocalories from sugar & 0.035 & 0.650 \\
Grams of trans fat & -0.015 & 0.841 \\
Percent of total kilocalories from saturated fat & 0.079 & 0.299 \\
\hline
\end{tabular}




\section{Scatter Plots for 35 Participants:}

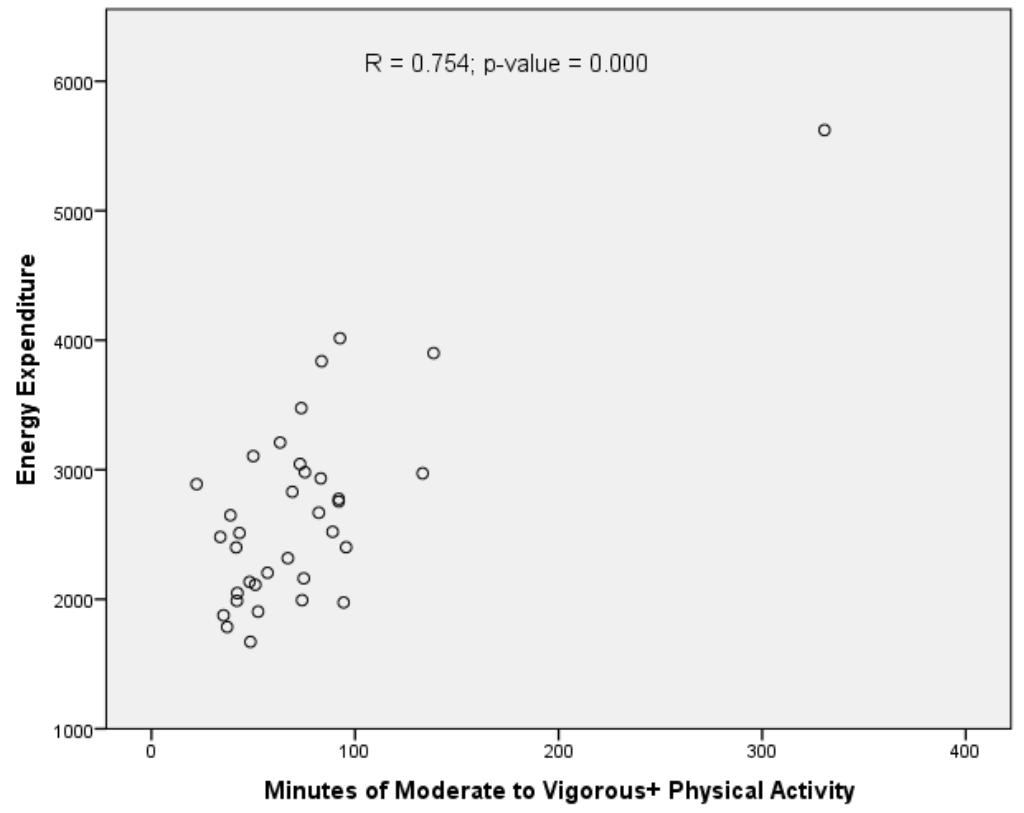

Figure 1. Energy expenditure vs. minutes of moderate to vigorous+ physical activity

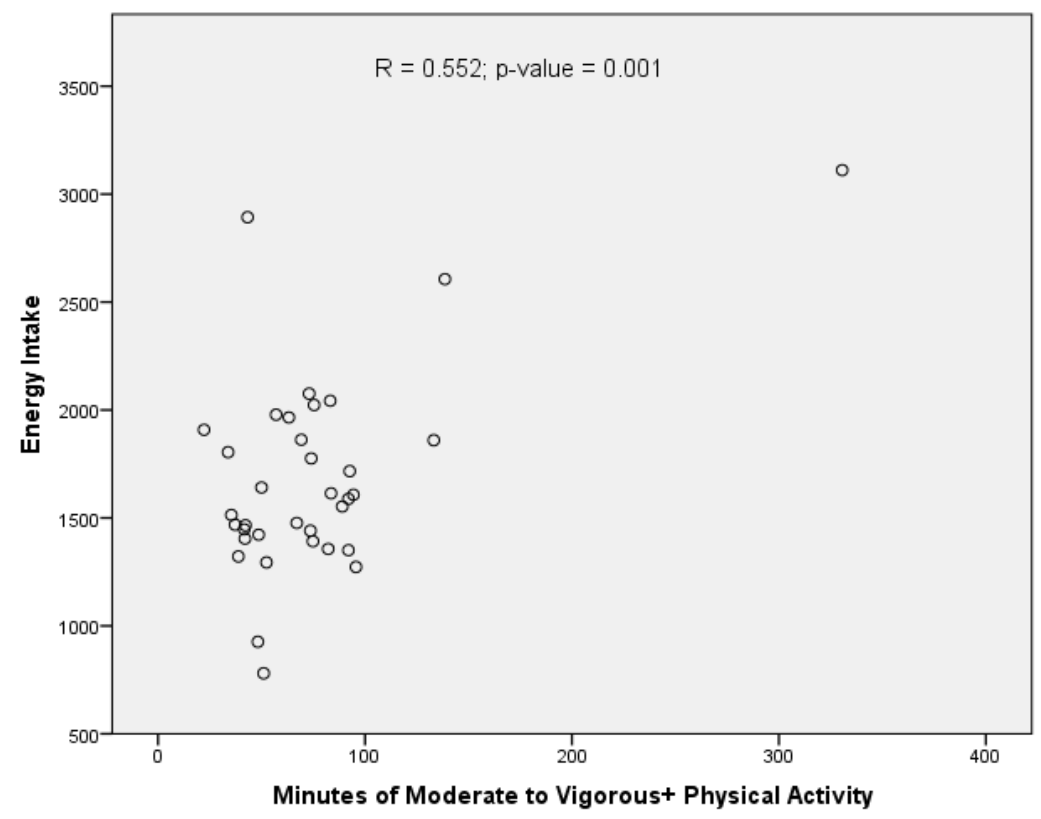

Figure 2. Energy intake vs. minutes of moderate to vigorous+ physical activity 


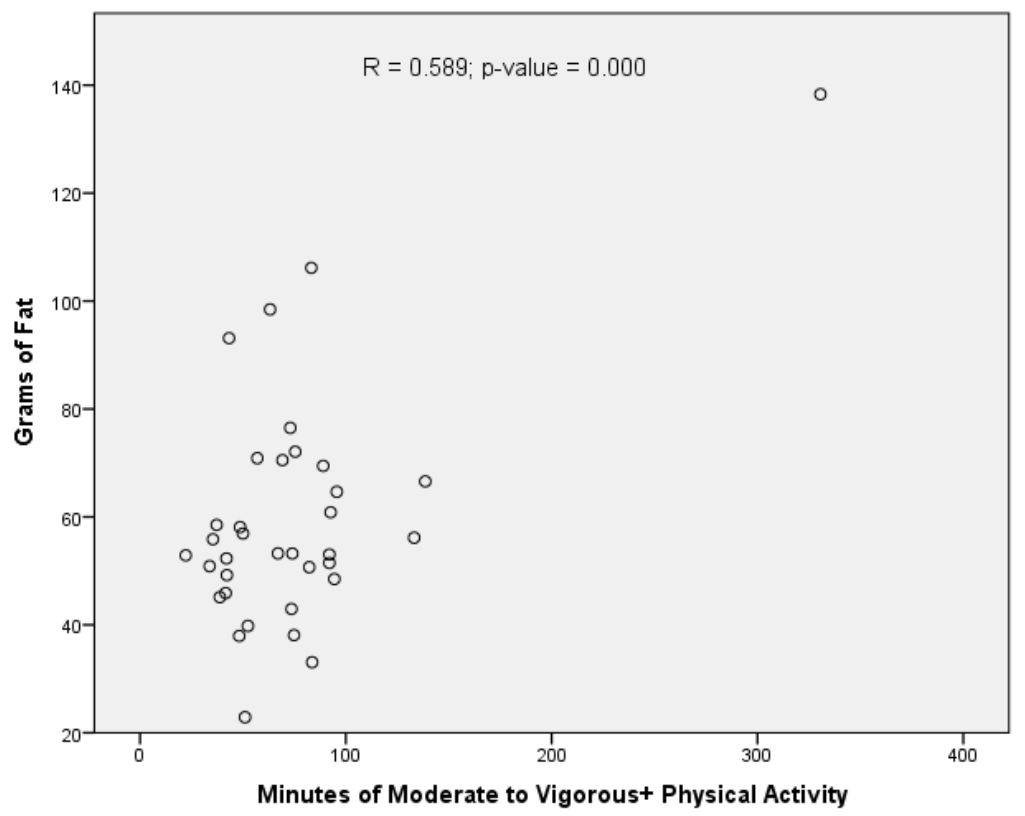

Figure 3. Grams of fat vs. minutes of moderate to vigorous+ physical activity

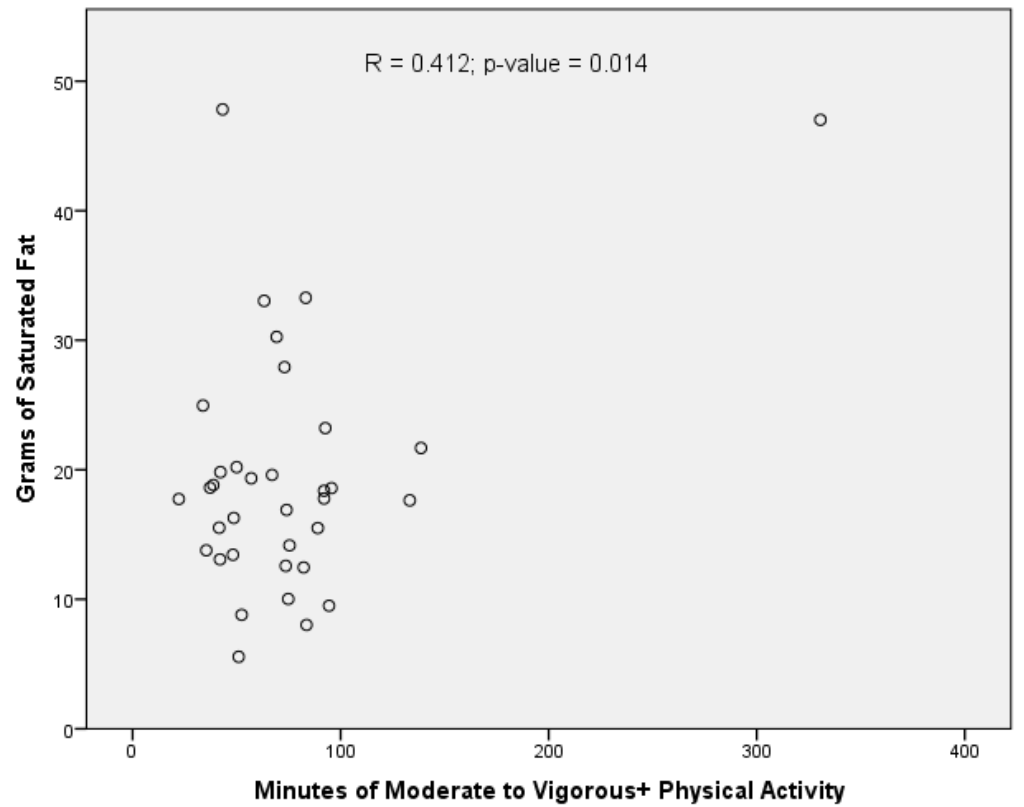

Figure 4. Grams of saturated fat vs. minutes of moderate to vigorous+ physical activity 


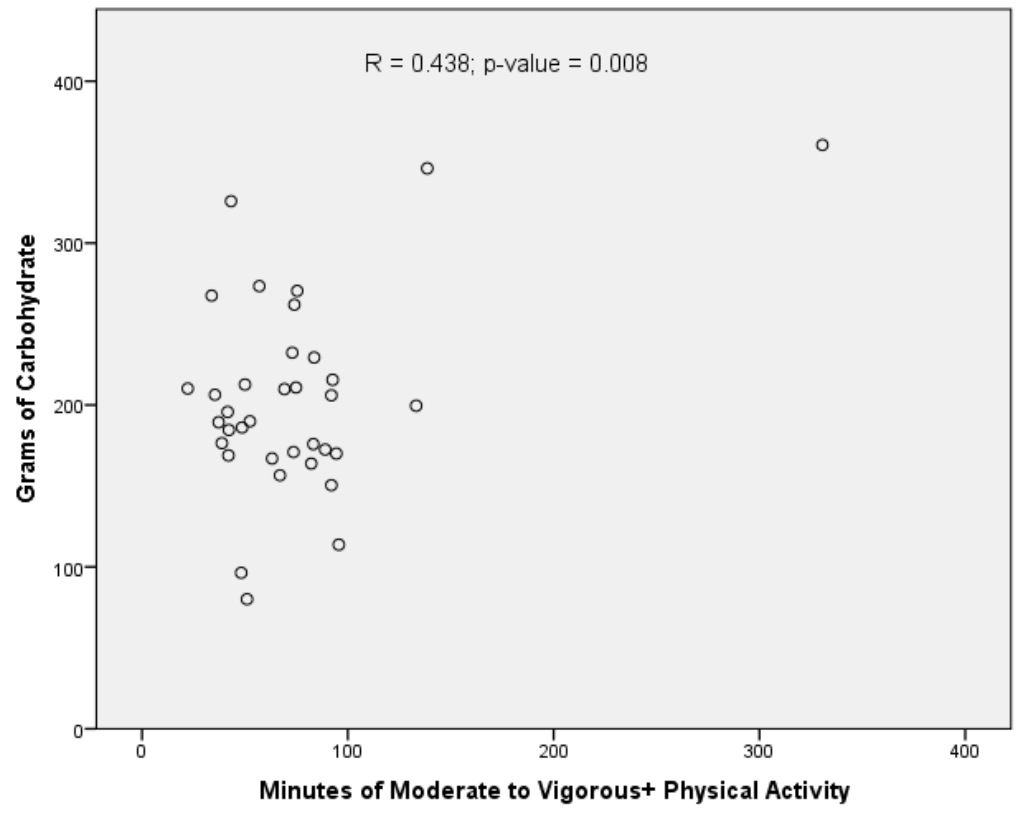

Figure 5. Grams of carbohydrate vs. minutes of moderate to vigorous+ physical activity

\section{Scatter Plots for All Daily Diet and Physical Activity Pairs:}

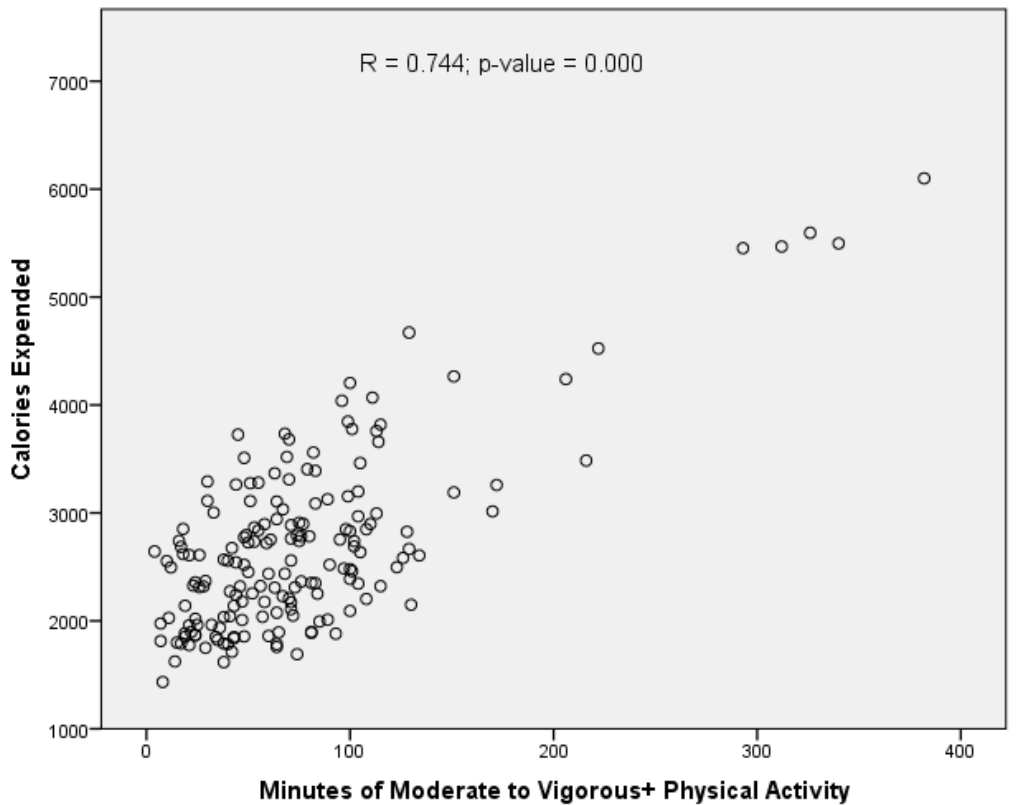

Figure 6. Calories expended vs. minutes of moderate to vigorous+ physical activity 


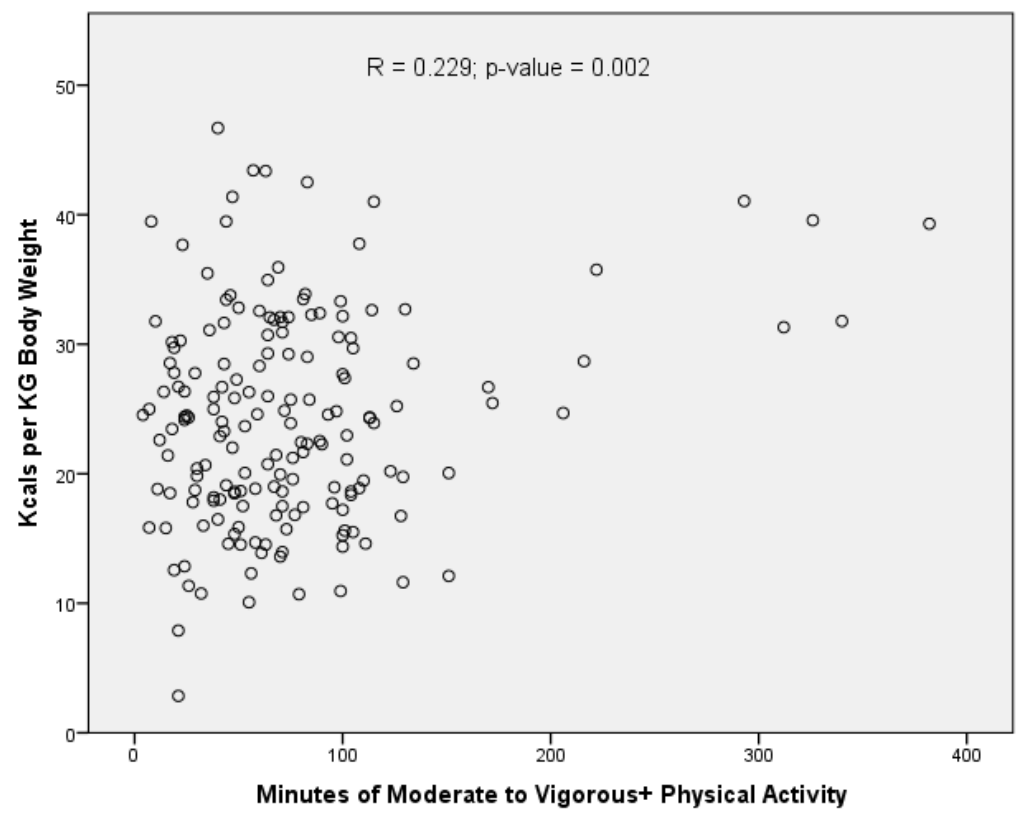

Figure 7. Kilocalories per kilogram of body weight vs. minutes of moderate to vigorous+ physical activity

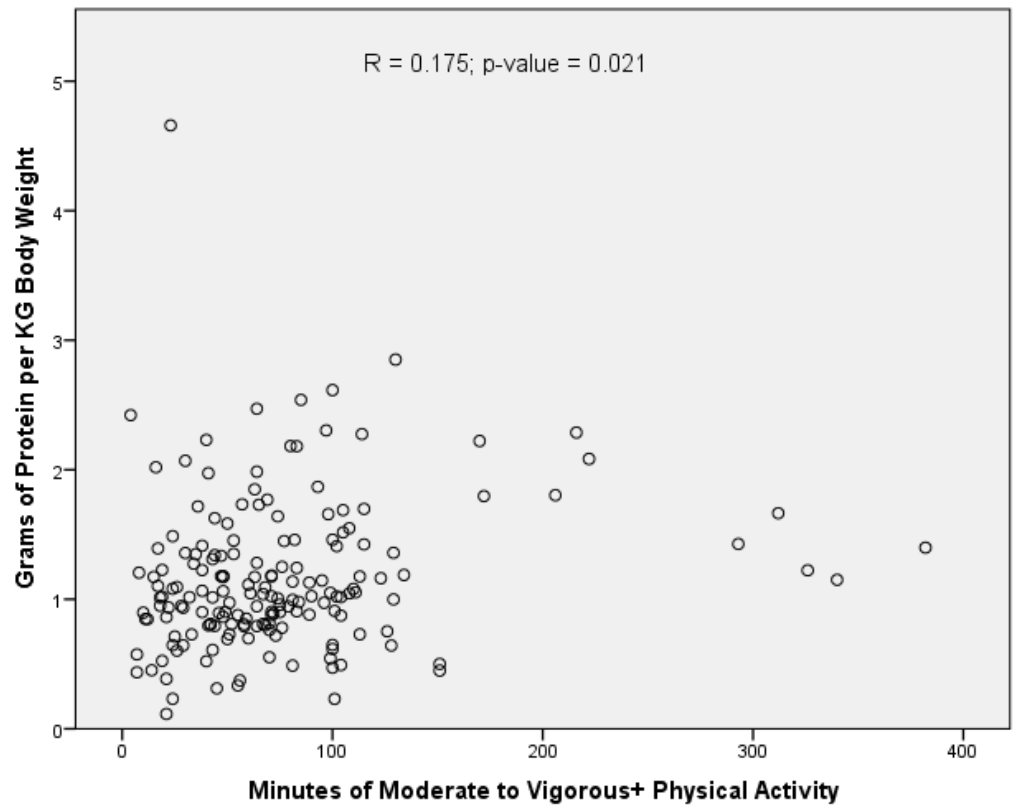

Figure 8. Grams of protein per kilogram of bodyweight vs. minutes of moderate to vigorous+ physical activity 


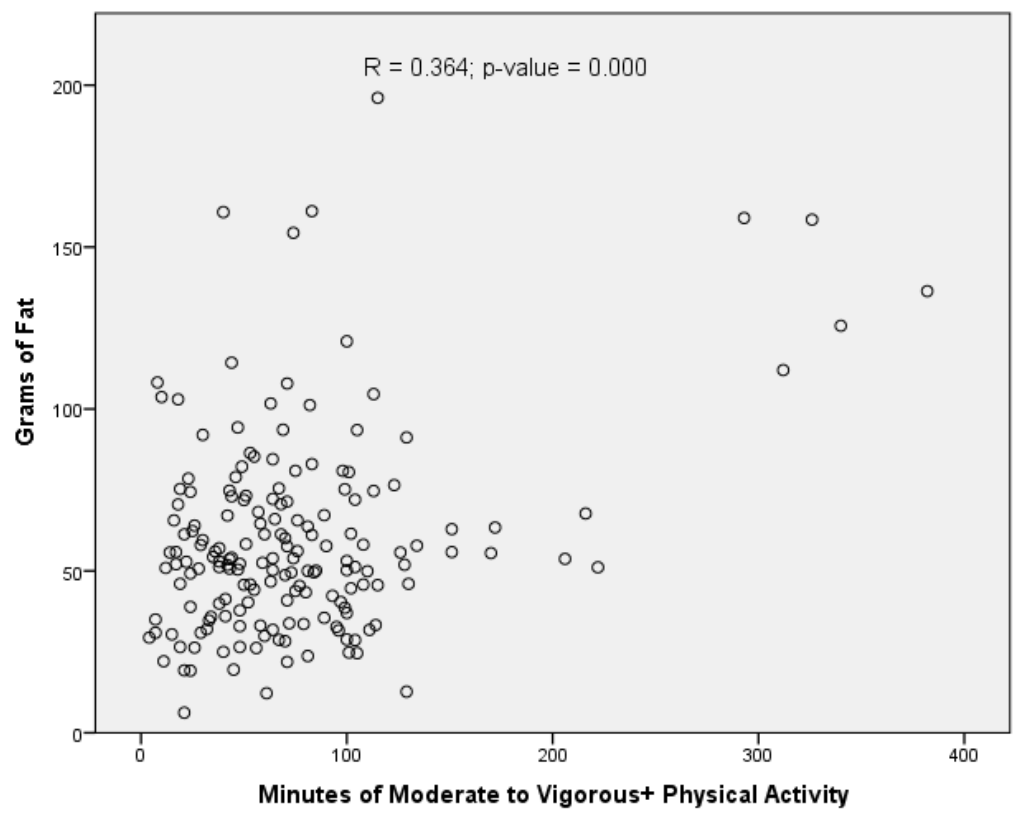

Figure 9. Grams of fat vs. minutes of moderate to vigorous+ physical activity

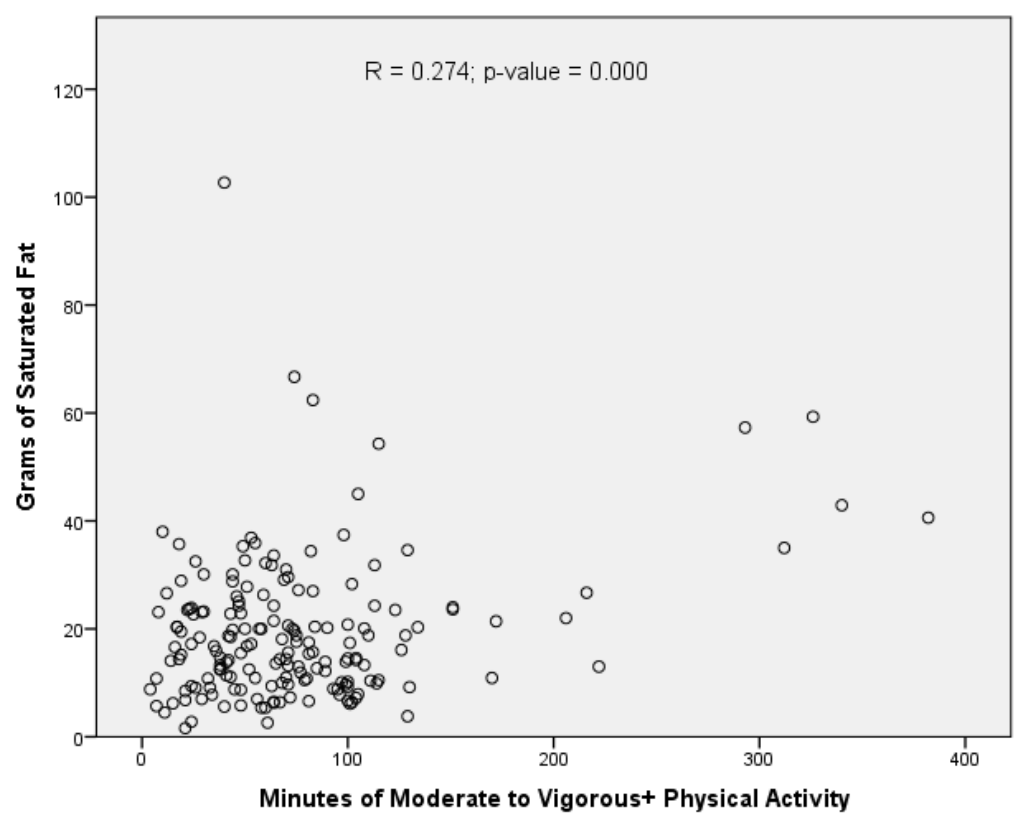

Figure 10. Grams of saturated fat vs. minutes of moderate to vigorous+ physical activity 


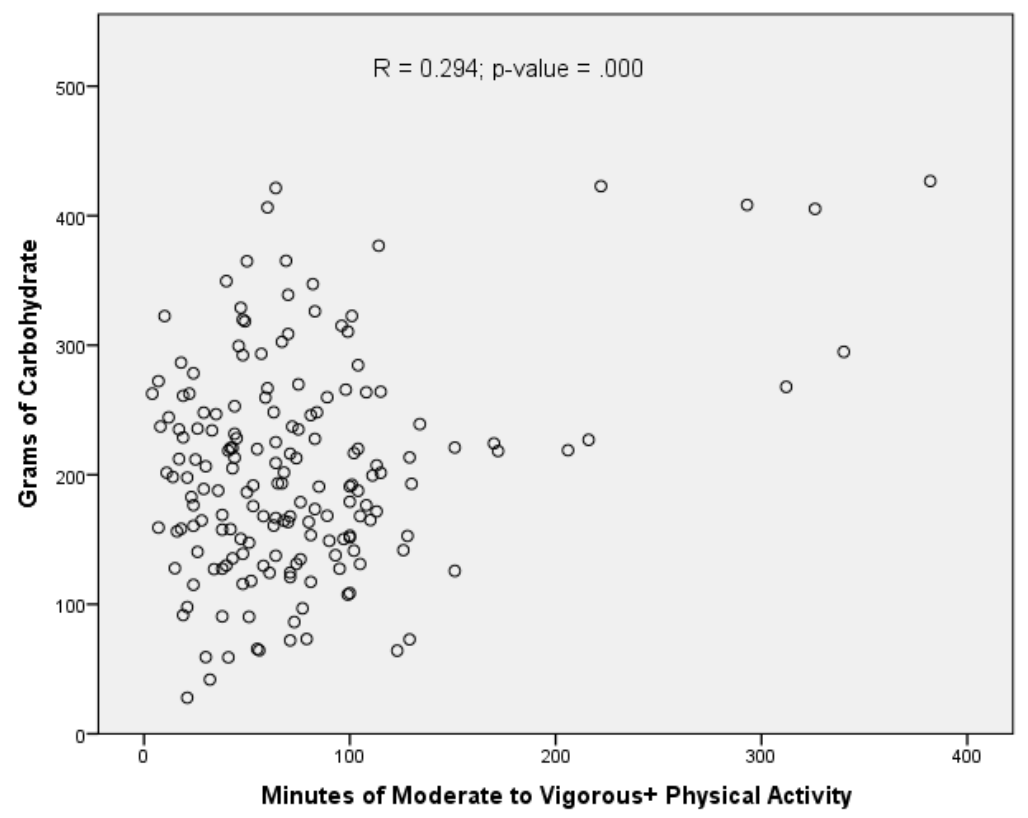

Figure 11. Grams of carbohydrate vs. minutes of moderate to vigorous+ physical activity

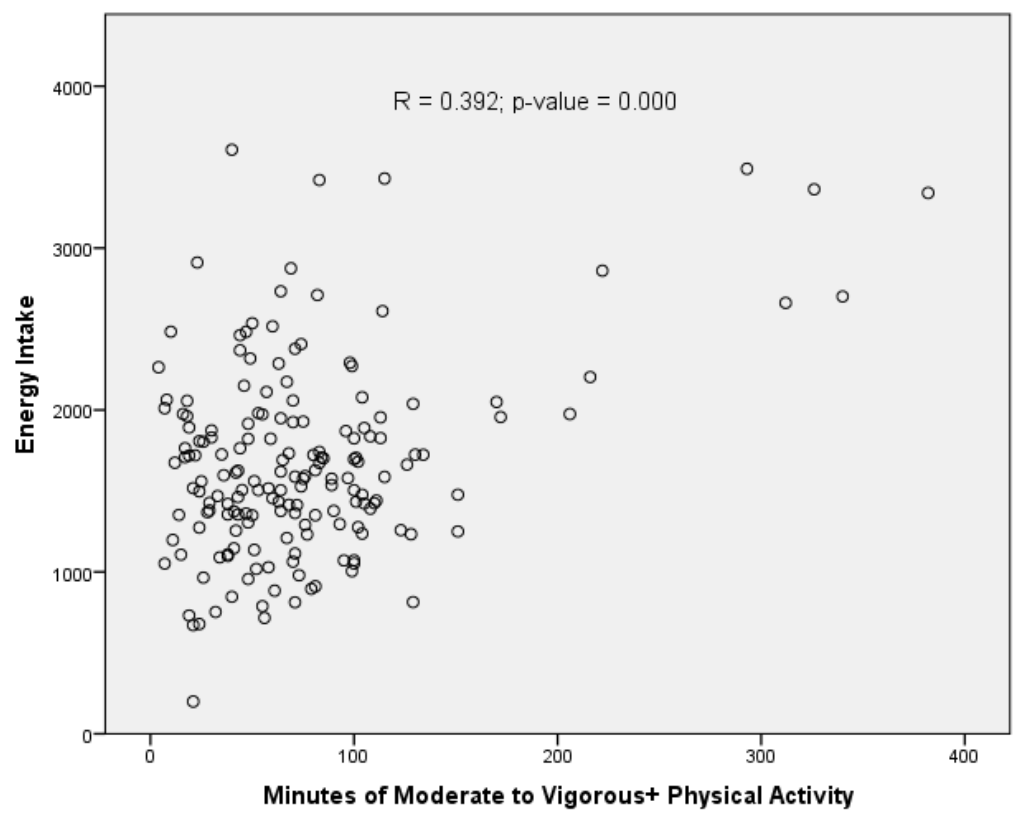

Figure 12. Energy intake vs. minutes of moderate to vigorous+ physical activity 


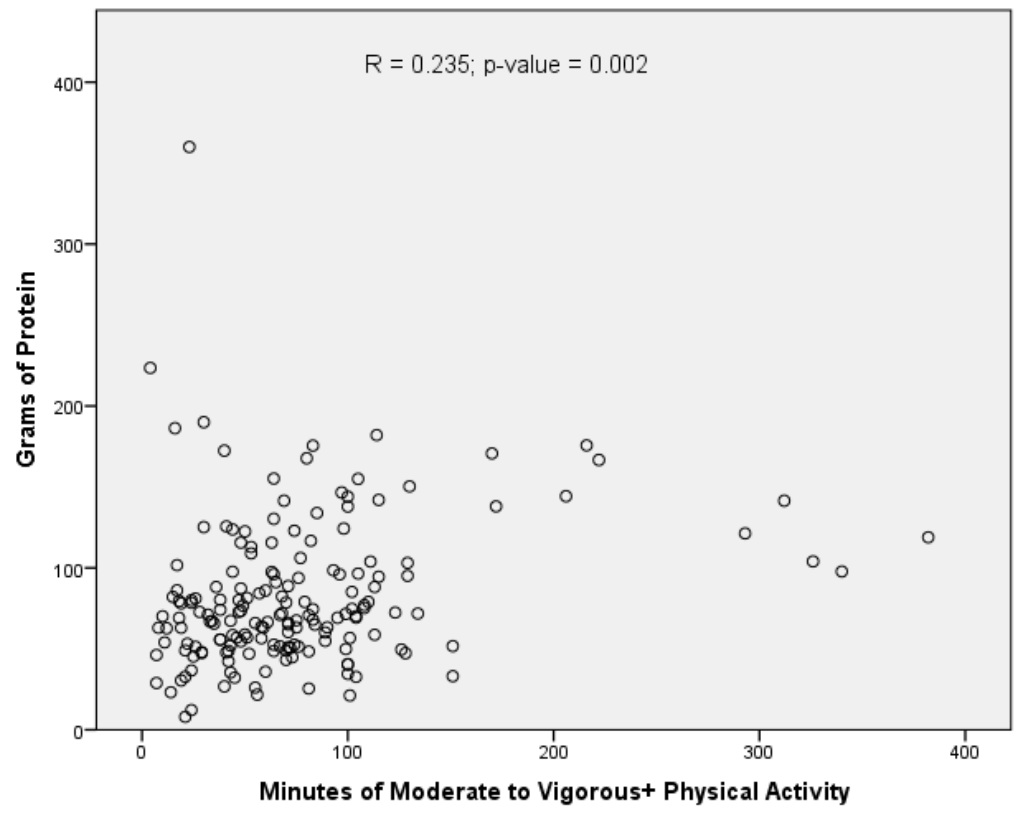

Figure 13. Grams of protein vs. minutes of moderate to vigorous+ physical activity

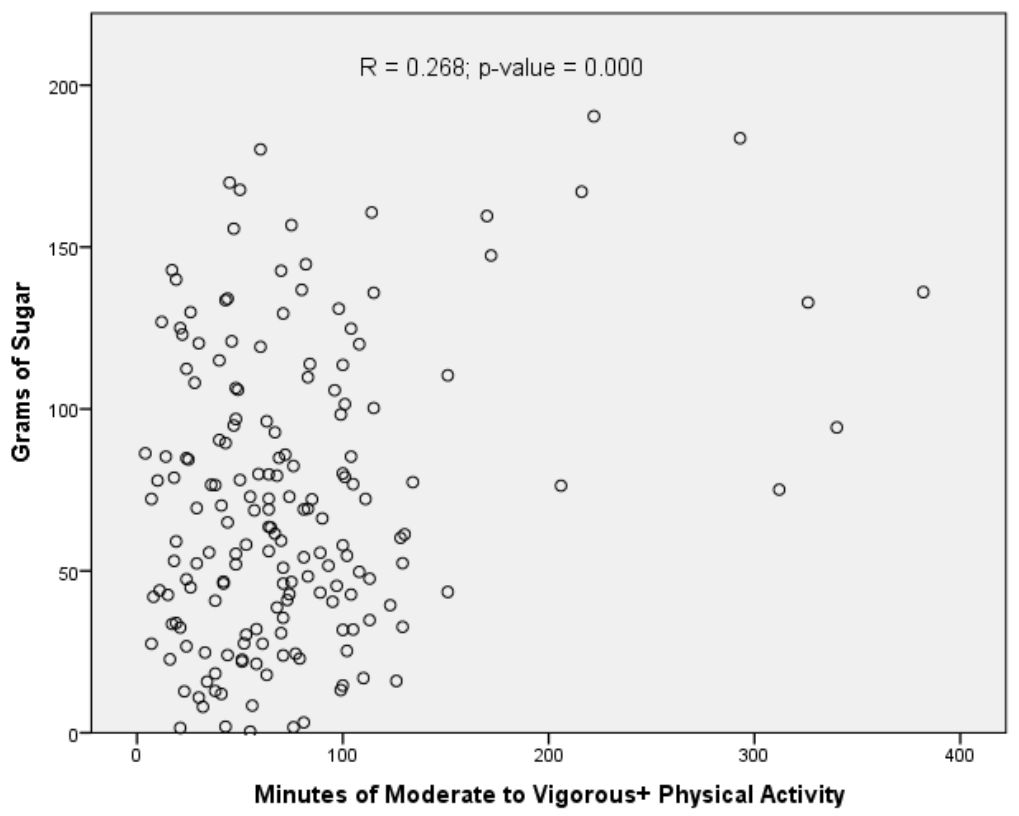

Figure 14. Grams of sugar vs. minutes of moderate to vigorous+ physical activity 


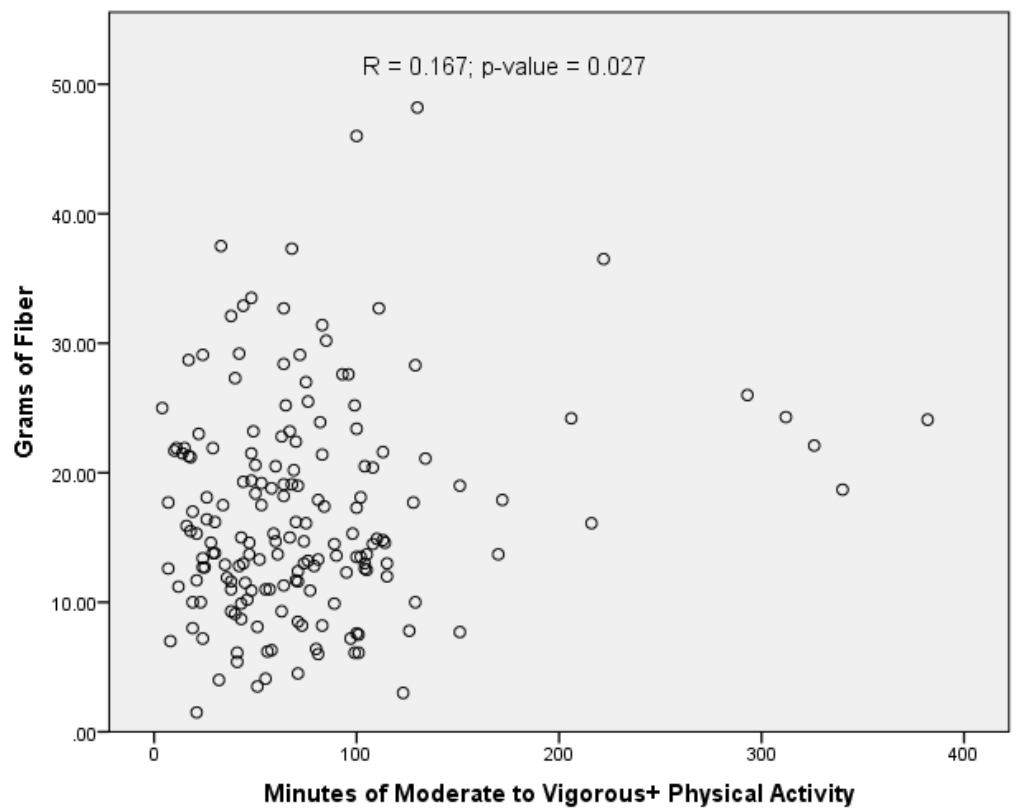

Figure 15. Grams of fiber vs. minutes of moderate to vigorous+ physical activity 


\section{Discussion}

This study set out to assess the association of moderate to vigorous+ physical activity and the intake of total kilocalories, sugar, and saturated fat in undergraduate college students. All data was analyzed twice; once as averages for each participant and once by using each day of each participant as a separate data point. Therefore, the variables examined yielded significant results for neither, one, or both analyses.

There was a significant positive correlation between moderate to vigorous+ physical activity and the intake of total kilocalories in a 24-hour period for both methods of analysis. While no studies were found that validated these results, Scarapicchia, Sabiston, \& Faulkner (2015) determined that males are more likely than females to meet dietary and physical activity recommendations. While Scarapicchia et al. (2015) did not specifically reference an increase in kilocalories in response to an increase in physical activity, males are more likely to meet dietary recommendations and thus an increase in kilocalories with an increase in physical activity. The current study supports this data. On average, males participated in 102.4 minutes of moderate to vigorous+ physical activity and consumed 2,108.7 kilocalories per day, while females engaged in an average of 63.9 minutes of moderate to vigorous+ physical activity and consumed an average of 1,514.9 kilocalories per day.

Regarding the impact of moderate to vigorous+ physical activity on sugar intake, there was a significant positive correlation seen when all diet and physical activity pairs were analyzed, but no significant relationship was found when the data was analyzed as averages for each participant. This finding could be explained if the majority of participants consumed an increased amount of sugar due to elevated participation in moderate to vigorous+ physical activity on only half of the days they recorded their diet and physical activity. This would 
emerge as a significant positive correlation when each of their days were analyzed separately. However, when each participant's data was averaged, the significant amount of sugar consumed and physical activity conducted on half the days would have spread between all days, which then would have produced the insignificant results. Another explanation could be the difference in the number of data points for each analysis; there are more data points when all daily diet and physical activity pairs are analyzed than when the averages are analyzed. This increase in sugar intake is corroborated through a study by Fayet, Flood, Petocz, \& Samman (2014) in which female participants engaged in moderate physical activity and consequently consumed two extra servings of food per day, consisting of empty calories including added sugar. While the current study did not differentiate between natural and added sugars, both males and females consumed more than $10 \%$ of their total kilocalories from sugar: $18 \%$ and $15 \%$, respectively. While these numbers contain both natural and added sugars, it is possible that both genders consumed more than $10 \%$ of their total kilocalories from added sugar, which is more than the recommended amount.

The grams of saturated fat variable was significantly and positively correlated with minutes of moderate to vigorous+ physical activity in both analyses. However, the analysis which used the averages for each participant was significant at the $\mathrm{p}<0.05$ level while the analysis which evaluated each day separately was significant at the $p<0.01$ level. This difference in significance may have a similar explanation to the one posed above: the amount of saturated fat consumed may have greatly varied between days of each participant's diet, which makes it significant to the 0.01 level when each day is analyzed separately, but when the grams of saturated fat are averaged across all days of each participant's diet, there is less variance which leads to a 0.05 significance level. Also similar to the previous explanation, the difference 
in significance level could also be due to the difference in the number of data points for each analysis; there are more data points when all daily diet and physical activity pairs are analyzed than when the averages are analyzed. It is recommended that saturated fat represent no more than $10 \%$ of a person's diet; in larger amounts, saturated fat may be considered a source of empty calories (“2015-2020 Dietary Guidelines,” 2016). In the current study, the average saturated fat intake for females and males was determined to be $10.1 \%$ and $10.9 \%$, respectively. Therefore, while the females in the current study were found to consume just slightly more than $10 \%$ of total kilocalories from saturated fat on average, this finding also relates to the research of Fayet et al. (2014), in which females engaged in moderate physical activity and consumed two extra servings of empty calories per day.

While the results of this study do support both research hypotheses, it is necessary to take all results into account, specifically, the non-significant results of this study. Two important nonsignificant variables found in this study are percent of total kilocalories from saturated fat and percent of total kilocalories from sugar. These variables indicate that when participants engaged in moderate to vigorous+ physical activity, the percentage of their total kilocalories from sugar and saturated fat did not significantly change. Therefore, it can be inferred that while increased moderate to vigorous+ physical activity is associated with increased grams of sugar and saturated fat, other analyzed nutrients also increase at similar rates.

The hypotheses stated in this research study, and the results which either support or refute these hypotheses, offer only a glimpse into the participants' diets. In order to determine whether the increase in kilocalories consumed as a result of moderate to vigorous+ physical activity was of high quality and nutrient-dense or low quality and consisting of empty kilocalories, the participants' diets were also analyzed for grams of fiber and grams of trans fat. Grams of fiber 
was significant only when each day of diet data was analyzed separately. Neither method of analysis revealed grams of trans fat to be significant. As the grams of fiber variable was significant when each diet day was analyzed separately, and neither method of analysis displayed significance for grams of trans fat, we can reasonably conclude that when participants consumed more kilocalories as a result of moderate to vigorous+ physical activity, these foods contained fiber, but not trans fat. This finding is consistent with the results of a study by Hebden, Chan, Louie, Rangan, \& Allman-Farinelli (2015), in which participants with increased physical activity placed more importance on consuming foods with high nutritive value than foods that tasted good. However, it could be argued that the same phenomenon is occurring with grams of fiber as occurred with grams of sugar and saturated fat. While we cannot analyze the data for percent of total kilocalories from fiber, we can reasonably assume that fiber, like sugar and saturated fat, simply increased in proportion with other nutrients when moderate to vigorous + physical activity increased. On average, participants consumed 10 grams of fiber for every 1,000 kilocalories (Table 6).

Other dietary variables not directly mentioned within the current study's research hypotheses include grams of total fat, protein and carbohydrate. Grams of total fat and carbohydrate were both significant and positively correlated with moderate to vigorous + physical activity for both methods of analyses. Grams of protein was significant and positively correlated with moderate to vigorous+ physical activity only when all diet days were analyzed separately. From these results, it can be concluded that there was a greater increase in the consumption of total fat and carbohydrate than protein when participants increased their moderate to vigorous+ physical activity. These findings relate back to the increase in grams of sugar, fiber and saturated fat as sugar and fiber are types of carbohydrate and saturated fat is a subcategory of total fat. 
This study has several possible limitations. First, all dietary intake data was self-reported, which can be especially erroneous in terms of total energy intake (Subar et al., 2015). Adolescents and athletes have been shown to under-report their energy intake (Hill \& Davies, 2001). Second, while physical activity data was recorded with an activity tracker, the activity tracker used in this study was equipped with a 3-D accelerometer, but not a heart rate monitor. This means, if a participant conducted physical activity without moving their wrist that held the activity tracker, their activity was not accurately recorded. An example of this is biking, where a person's legs pedal the bike, but their hands remain stationary on the bike handles. Finally, all participants in this study were undergraduate college students enrolled in an introductory level kinesiology course. As such, these results may not be generalizable across all undergraduate students in different fields of study.

Future studies should examine whether the increase in energy intake is from the same foods participants regularly consume or whether they choose different foods after engaging in moderate to vigorous+ physical activity. Similarly, future studies should observe more closely the difference in increase in carbohydrate and fat intake versus protein intake when study participants engage in moderate to vigorous+ physical activity. In addition, students from different disciplines should be included in these future studies to ensure findings can be generalized to all undergraduate college students. Finally, subsequent studies should utilize a physical activity tracker equipped with a heart rate monitor as well as a 3-D accelerometer so all types of physical activity may be accounted for. This information will allow researchers and health professionals alike to implement effective nutrition and healthcare interventions for all undergraduate college students.

This research study examined undergraduate students' diets and determined when this 
population group increased their moderate to vigorous+ physical activity, they simultaneously increased their energy intake. Comparably, these participants increased all three macronutrients in response to increased moderate to vigorous+ physical activity, although the consumption of carbohydrate and total fat increased more than the consumption of protein. These results may indicate a disparity between college students' habits and established recommendations for healthy eating. 


\section{CHAPTER II: EXTENDED LITERATURE REVIEW}

Poor dietary and physical activity habits can lead to health problems such as obesity, diabetes and other chronic diseases later in life (LaCaille, Dauner, Krambeer, \& Pedersen, 2011). Students in college may form new dietary and physical activity habits (Deforche, Van Dyck, Deliens, \& De Bourdeaudhuij, 2015). These new habits can positively or negatively impact their health. Oftentimes, college students are living on their own for the first time. This allows them more freedom in what they eat, and when and how often they participate in physical activity (Arnett, 2015).

The following studies cited in this literature review examined the energy intake and physical activity of college students but did not specifically look at the flux of energy intake in participants after physical activity, nor did these studies analyze empty calorie intake in relation to a specific physical activity level in a college student population. These are the gaps in the current literature on college students and related physical activity and energy intake patterns. The current study attempted to fill these aforementioned gaps.

\section{Energy Intake in College Students}

College students often participate in unhealthy dietary behaviors (Lewis et al., 2009). Unhealthy dietary behaviors practiced within the college student population include disordered eating (Quick \& Byrd-Bredbenner, 2013), and high consumption of unhealthy, processed foods due to time constraints, work schedules (Gorgulho et al., 2012), and living conditions (El Ansari, Stock, \& Mikolajczyk, 2012). Research studies have looked into factors influencing students’ food choices (Hebden et al., 2015) and nutrition interventions focused on healthy food choices for college students (Seward et al., 2016). A lifestyle of poor dietary quality can lead to increased risk of obesity and other chronic diseases (Gorgulho et al., 2012). 
Research conducted by Quick \& Byrd-Bredbenner (2013) found college students from three large, public United States universities often participated in disordered eating. The results indicated one-quarter of women and one-fifth of men had participated in dietary restraint lasting longer than eight hours at least once within the previous 28 days (Quick \& Byrd-Bredbenner, 2013). Dietary restraint was defined within this study as the restriction of a person's food intake. Within the same study, it was found that one in seven participants had reported participating in binge eating. Binge eating was defined within the study as consuming large amounts of food in a short time period while simultaneously feeling out of control (Quick \& Byrd-Bredbenner, 2013). One-fourth of study participants had engaged in binge eating within the past 28 days.

While dietary patterns are important factors in the health of college students, dietary quality is of similar, if not greater, importance. The dietary quality of college students was investigated in the following two research studies. In a study by El Ansari, Stock, \& Mikolajczyk (2012), it was found that college students' dietary behaviors depended largely on whether the students lived at home with their parents or on their own. Another study looked at working college students and their corresponding dietary behaviors (Gorgulho et al., 2012). It was determined within these two studies that participants who either lived away from home or worked while attending college consumed a less nutrient-dense diet than students who lived at home and/or did not work while attending college. Participants living away from home were found to consume less fruits, vegetables, and meats than students who lived at home with their parents (El Ansari et al., 2012). Similarly, Gorgulho et al. (2012) found that working students had a poorer dietary quality as compared with non-working students. The working students were found to consume foods and meals high in sodium and sugar, and low in fruits and whole grains. A lack of time was cited as one reason working students consumed unhealthy foods. A study by 
Martinez, Harmon, Nigg, Bantum, \& Strayhorn (2016) also found that time was the primary barrier to healthy cooking and eating in a college student focus group.

Another study looking at dietary quality used green, yellow, and red labels attached to food items in college cafeterias to signify the nutrient content of each food item (high, medium, and low, respectively) (Seward et al., 2016). The students filled out surveys during the intervention and 58\% reported using the colored food/nutrient labels at least a few times each week, while $73 \%$ of students reported within the survey that they would like the food/nutrient labels to continue even after the study was complete (Seward et al., 2016). While the results from the survey seem to indicate a favorable change in attitude toward a healthier diet and higher nutrient intake in this particular group of college students, the study results found the colored food labels had no significant effect on students' actual consumption of nutrients (Seward et al., 2016).

In a qualitative study by Smith-Jackson \& Reel (2012), freshman, female college students were interviewed about their dietary behaviors. The majority of these participants believed the "Freshman 15" was inevitable during the first year of college. The "Freshman 15" is the belief that college students gain 15 pounds during their first (freshman) year of college (Mihalopoulos, Auinger, \& Klein, 2008, p. 15). The participants also noted that their newfound food independence contributed to their weight gain, as well as the low availability and high cost of fruits and vegetables, few grocery stores within walking distance to campus, and a high intake of alcohol (Smith-Jackson \& Reel, 2012). While these participants were listing reasons for weight gain, these reasons were also barriers to healthy eating, just as Gorgulho et al. (2012) and Martinez et al. (2016) found time constraints as the primary barrier to healthy food consumption in their research with college students. Contrary to popular belief, one research study showed 
only half of college students gained weight during their freshman year of college, and those who did gain weight, only gained an average of 2.7 pounds during that first year of college (Mihalopoulos et al., 2008, p. 15). In another study by Zagorsky \& Smith (2011), the average weight gain of college freshman was found to be between 2.5 and 3.5 pounds This article also discovered that college students often continuously gain weight during as well as after their college years, not all at once during their freshman year as is the common belief (Zagorsky \& Smith, 2011). These two research studies show evidence that the average weight gain during a college student's freshman year is less than the common belief of 15 pounds.

In a study by Hebden et al. (2015), taste was determined to be the most important factor in food choice for the majority of college students. After taste, students chose foods based on availability, cost, and finally nutritional value, while the least important factors identified to influence students' food choices included smell and stimulatory properties (Hebden et al., 2015). In contrast to the majority of college students' food preferences, Hebden et al. (2015) found that students who participated in high levels of physical activity were more likely to choose and consume foods based on nutritional value, rather than taste. Furthermore, female students who reported high levels of physical activity placed more importance on choosing foods based on nutritional value than male students who also reported high levels of physical activity (Hebden et al., 2015). In this same study, college students with an increased health risk due to waist circumference were shown to choose foods to help them deal with stress and control their weight (Hebden et al., 2015). In terms of BMI, a study by Colby et al. (2017) found college students with higher BMIs generally exhibit lower fruit and vegetable consumption, while Hebden et al. (2015) determined no difference between BMI categories in how these college students select foods. 
The majority of college students have many barriers to consuming healthy, nutritious foods. These barriers include living on their own for the first time without having the time, skills and/or knowledge to cook and prepare healthy foods, societal pressure for their bodies to look a certain way, newfound food independence, a low availability and high cost of fruits and vegetables, a low number of grocery stores within walking distance to college campuses, high consumption of alcohol, and taste preferences. The multitude of barriers to healthy eating for college students impresses upon researchers the urgent need for substantial and effective nutrition interventions.

\section{Physical Activity in College Students}

Many studies have looked at physical activity in college students. These studies look at factors which may affect the prevalence, duration, intensity or type of physical activity. Current governmental physical activity guidelines for college-aged students recommend 150 minutes of moderate-intensity aerobic exercise or 75 minutes of vigorous-intensity aerobic exercise per week, along with two or more days of muscle-strengthening activity that targets all the major muscle groups (“Adults - 2008 Physical Activity Guidelines - health.gov,” 2017).

A study by Năsui \& Popescu (2014) found a positive correlation between physical activity level and medical students' grades. The more physical activity a medical student performed, the higher their grades were. Thus, a correlation may be drawn between physical activity and students' grades or academic performance.

Similarly, a study providing small monetary incentives for exercise identified a positive correlation between an experimental group that received a small, weekly monetary incentive for exercising (\$5.00/week) and the total amount of exercise the experimental group performed (Strohacker et al., 2015). However, this study also determined participation in exercise declined 
within the experimental group over time, demonstrating that while small monetary incentives increase physical activity participation in the short-term, more research should be conducted to determine at what point and why small monetary incentives become reduced in their effectiveness regarding participation in physical activity. In addition, the participants within this study were all female and thus the results cannot be generalized to the entire population (Strohacker et al., 2015). Another study with a similar methodology should be conducted to determine whether the results can be applied to males as well as females. Regarding a decline in physical activity during college, one qualitative study discovered primary barriers to physical activity for college students included cost, accessibility, time, lack of energy, and intimidation due to lack of skills (Martinez et al., 2016).

Similar to the study by Strohacker et al. (2015), the prevalence of physical activity was also seen to increase in female college students who participated in group fitness classes at a university recreational center (Gu, Zhang, \& Smith, 2015). This study found that increased group cohesiveness led to having higher levels of self-efficacy and Individual Attraction to the GroupTask, defined as an individual's productivity, personal goals and attraction to the group's task (Gu et al., 2015). These traits subsequently lead participants to increase their involvement in group activity programs. Analogous to the previous study by Strohacker et al. (2015), all participants in this research study by Gu et al. (2015) were female, and thus a similar study should be conducted with both male and female participants before these results can be generalized to the entire college student population.

Kemmler, von Stengel, Kohl, \& Bauer (2016) determined that physical activity did not decrease during college, but exercise (which was defined within the research study as individual or group sports) did decline in both students studying dentistry as well as students studying 
physical education when compared to other majors. However, this same research study also noted that dental students gained twice as much fat as lean body mass, whereas physical education students gained solely lean body mass during this same timeframe. Decreased exercise volume and intensity were found to be the biggest factors in the loss of fitness and corresponding fat gain in dental students (Kemmler et al., 2016). A study by Colby et al. (2017) detected an inverse relationship between BMI and physical activity. The differences in results seen in the study by Kemmler et. al (2016) may be due to the two groups of students studied. It is possible that college students who major in physical education are more aware of their physical activity and exercise levels than college students who major in dentistry. It is also possible that the coursework for students studying physical education includes more physical activity than the coursework for students studying dentistry. The differences between these two college majors may account for the differences seen in lean vs. fat mass as well as the fitness level in these two student populations.

A study by Allom, Mullan, Cowie, \& Hamilton (2016) determined that the theory of planned behavior worked well in predicting physical activity levels in first generation college students. The theory of planned behavior states that a specific behavior arises from the combination of intention and perceived behavioral control (Allom et al., 2016). Through this study, the intentions and habits of these students towards physical activity were identified as particularly important in determining their physical activity patterns. In terms of habit, the article stated these actions were generally cued by something else in a person's life. A cue might be the time of day, which could carry over to a college setting. However, if the cue is a running partner, this partner may not be around the college setting and thus this habit would not carry over to college. The students' intentions to participate in physical activity was found to exert an 
independent effect on physical activity behavior. Habit strength and intention were concluded to influence physical activity behavior independently of one another (Allom et al., 2016).

While sports participation generally decreases between high school and college, physical activity does not. College students' physical activity behaviors may change based on their field of study, incentives, and whether they participate in physical activity by themselves or with a group. College students' habits and intentions towards physical activity are strong predictors of actual physical activity participation.

\section{Energy Intake and Physical Activity in College Students}

Several studies have examined the relationship between energy intake and physical activity in college students. These studies explore the reasoning behind differing patterns of energy intake and physical activity, the differences that can be seen between male and female college students, and changes in these behaviors between high school and college. These studies offer insight into basic energy intake and physical activity patterns of college students.

In a study by Scarapicchia, Sabiston, \& Faulkner (2015), it was found that male college students are more likely to meet the daily requirements for moderate to vigorous physical activity, strength training, and fruit and vegetable intake than their female counterparts. While a study by LaCaille et al. (2011) found that dietary and physical activity habits in college students were determined by a mix of motivation, self-regulatory skills, and social and physical

environments. Students with high physical activity levels have been found to choose foods based on nutritional value rather than taste (Hebden et al., 2015).

Regarding solely a female college student population, Fayet, Flood, Petocz, \& Samman (2014) found the majority of participants engaged in moderate physical activity, but less than half of the participants met the requirements for cereals, vegetables, fish and meat. This led to a 
low intake of iron, zinc, selenium, vitamin B12 and omega-3 fatty acids among female college students. This study's results demonstrated the inadequate nutrient intake of female college students who partake in moderate physical activity. Similarly, a study conducted by Deforche et al. (2015) followed 291 students from their last year in high school to the beginning of their second year in college. The researchers determined these students had decreased their participation in sports during their transition from high school to college, over the course of the study. These participants also decreased their intake of fruits, vegetables, fiber and calcium, while simultaneously increasing their consumption of alcohol during this time. This study demonstrates lower sports participation in college students may be associated with a lower intake of nutrient-dense foods.

Energy intake habits and physical activity routines of college students are determined by their motivation, self-regulatory skills, social environment, and physical environment. Research shows as physical activity increases within a college student population, the corresponding energy intake becomes more nutrient dense. Males have been found to meet more energy intake and physical activity recommendations than females, although research has shown a decrease in physical activity and the consumption of fruits, vegetables, fiber, and calcium among both genders during the transition from high school to college.

\section{Empty Calorie Intake and Physical Activity in College Students}

Students often arrive at college with a newfound independence over their lifestyle. They are now in control of what they eat and when, as well as if and how often they partake in physical activity. Their newly acquired food independence often leads to nutrient-poor food choices, or empty calories, in the form of candy, chips, soda, or alcohol. The following studies address the relationship between empty calories and physical activity in college students. 
A sample of college females within which the majority participated in moderate physical activity were found to consume up to two extra servings of foods each day compared with the Australian Guide to Healthy Eating. These extra servings of food were often comprised of empty calories (Fayet et al., 2014). College students studied from their last year in high school to the beginning of their second year in college increased empty calorie consumption in the form of alcohol and a decreased participation in sports activities during this time period. These changes lead to weight gain in the male participants (Deforche et al. 2015).

In a sample of 274 college students, Bryant, Darkes, \& Rahal (2012) determined that half of these students reported exercising at least $25 \%$ of the time after ingesting alcohol in order to off-set the calories they consumed while drinking. Female and male participants were equally likely to participate in this behavior (Bryant et al., 2012). A similar study by Musselman \& Rutledge (2010), also identified a positive correlation between alcohol consumption and physical activity levels in college student participants. Higher alcohol consumption lead to higher levels of physical activity in these participants (Musselman \& Rutledge, 2010). In contrast, Barry, Whiteman, Piazza-Gardner, \& Jensen (2013) observed a slight negative association between alcohol consumption and exercise in females, but a positive association between these same two variables in males. As a result, the authors concluded that males are more likely to use exercise to off-set the effects of drinking alcohol than females (Barry et al., 2013).

Many empty calories in a college student's diet come from alcohol. Physical activity is sometimes seen by students as an antidote to consuming too many calories from alcohol. One research study determined half of the study's participants engaged in more physical activity after consuming alcohol. Another study found a positive correlation between physical activity and 
alcohol consumption across all genders, while still another research study identified males as being more prone to this positive correlation than females.

\section{Saturated Fat Intake in College Students}

The American government recommends consuming less than $10 \%$ of total kilocalories from saturated fat ("2015-2020 Dietary Guidelines," 2016). Excessive amounts of saturated fat can be categorized as empty calories. The following studies have investigated college students and their consumption of saturated fat.

Ćatović, Dervisević, Lepara, Gorčević, \& Gorčević (2014) conducted a study looking at the average fat intake of 60 graduate students at a university in Bosnia and Herzegovina. This study determined $55.56 \%$ of males and $51.52 \%$ of females consumed more saturated fat than is recommended by the World Health Organization and the National Academies Press. In this group of students, $33.34 \%$ of males had a normal BMI, while $53.33 \%$ were overweight and $12.33 \%$ were obese. In contrast, the group of female students who consumed more saturated fat than recommended were all within the normal BMI range (Ćatović et al., 2014). While these results are interesting, the participants live outside of the United States, and thus may have different diets and eating patterns than researchers may observe within the United States. While the study by Ćatović et al. (2014) utilized graduate students as research study participants, a similar study looking at saturated fat and cholesterol intake surveyed 231 undergraduate students at a university in Michigan (Yahia, Brown, Rapley, \& Chung, 2016). This study identified the mean saturated fat intake for all BMI ranges and determined they exceeded that of daily recommendations for all ranges. Regarding all study participants, $76.2 \%$ of females and $47.8 \%$ of males had a normal weight BMI; $17.1 \%$ of females and $35.8 \%$ of males were considered to be overweight; while $4.3 \%$ of females and $13.4 \%$ of males were in the obese BMI category (Yahia 
et al., 2016). These numbers align with the results of Ćatović et al. (2014), as both studies found that more men than women were in the overweight and obese categories. While this study examined saturated fat intake and BMI, the main objective was correlating the participants' intake of saturated fat with their nutrition knowledge. In doing so, this study found an inverse relationship between saturated fat intake and nutrition knowledge; the more nutrition knowledge a study participant had, the less saturated fat they consumed (Yahia et al., 2016).

Two research studies examined female and male college students who consumed more saturated fat than recommended by governmental guidelines. These studies found that males were more likely to be overweight or obese than their female counterparts. It was also determined the more nutrition knowledge college students had, the less saturated fat they consumed.

\section{Sugar Intake in College Students}

The American government recommends consuming less than $10 \%$ of total kilocalories from added sugar (CDC, 2016). As students transition from high school and living at home with parents to college and living by themselves, they find themselves free to consume foods they could not at home. Candy, soda, fruit juice, and sweetened coffee are just some of the foods and beverages with added sugar college students have nearly unlimited access to.

According to a research study by Jasti, Rubin, \& Doak (2017), college students with more knowledge of sugar-sweetened beverages consumed, on average, less sugar-sweetened beverages than those with less knowledge on the subject. This association was particularly strong in overweight college students. However, these students self-reported their weight and sugarsweetened beverage intake which may have led to the under-reporting of sugar-sweetened beverage intake and weight. Similarly, the study authors noted that students with more sugar- 
sweetened beverage knowledge may under-report their consumption of these drinks (Jasti et al., 2017).

Another study by O’leary, Hattersley, King, \& Allman-Farinelli (2012) identified college males as drinking slightly more sugar-sweetened beverages than college females. Carbonated soft drinks made up the largest percentage of sugary drinks consumed by males, while sweetened milk drinks made up the largest percentage of sugary drinks consumed by females. The second category for consumption of sugary drinks was fruit juice drinks for both males and females (O'leary et al., 2012). As with the study by Jasti et al. (2017), this study asked participants to self-report their beverage consumption. This is a limitation as the participants may have underreported their sugary beverage consumption.

In general, an increase in sugar-sweetened beverage knowledge lead to a decrease in the consumption of sugar-sweetened beverages. This association was particularly strong in overweight college students. Male students consumed more sugar-sweetened beverages than females with soda as their largest category, while females chose sweetened milk-based drinks more than any other type of sugar-sweetened beverage.

\section{Energy Balance}

Energy balance is the difference between kilocalories ingested from food, and kilocalories expended via activities of daily living and physical activity. If more kilocalories are ingested than expended, a positive energy state results. Reoccurrence of a positive energy state leads to weight gain. However, if more kilocalories are expended than ingested, a negative energy state results. Reoccurrence of a negative energy state leads to weight loss.

A study by Champagne et al. (2013) examined energy balance in 15 young adult females. It was found that corrective responses to energy intake and energy expenditure occur over a 
period of $3-6$ days. However, the participants in this study were all female and thus the results of this study cannot be generalized to the entire population. In a similar manner, all of the female participants were in school or careers related to dietetics. This segment of the population may be better informed on topics such as nutrition and healthy eating behaviors than people in school or a career of a different field. Thus, the results of this study may not be generalized across all study disciplines because the results may have been different if the participants were in a different career field, as such participants may not be as educated on healthy eating practices.

\section{Activity Tracker}

Physical activity trackers allow users to gain information relating to their personal daily fitness and exercise routines. Current physical activity monitors include wearable technology such as smart watches that contain hardware and an application which tracks and monitors specific fitness metrics (Kaewkannate \& Kim, 2016). In a study conducted by Jones, Seki, Mostul, \& Coste (2017), 29.49\% of college students, faculty, administrators, and staff at a college in Oregon reported owning an activity tracker.

The Polar A300 watch is an example of a commercially available activity tracker. This watch was validated in a study by Boeselt et al. (2016). Within this study, Boeselt et al. (2016) compared the Polar A300 to the previously validated Bodymedia-SenseWear activity tracker. It was found that when compared using linear regression analysis and Bland-Altman plots, there were no significant differences between steps, calories burned, daily activity time, and metabolic

equivalents (Boeselt et al., 2016). Within the same study, participants were asked to rate usability of both the Polar A300 and the Bodymedia-SenseWear based on system-, information-, and interface quality. The results showed higher favorability for the usability of the Polar A300 than for the Bodymedia-SenseWear. Another type of Polar watch was evaluated in a systematic 
review by Van Remoortel et al. (2012), this review found the Polar watch AW200 to have validity within categories of total energy expenditure, activity energy expenditure, steps, and physical activity intensity (Van Remoortel et al., 2012).

Two separate Polar activity trackers have been validated against other activity trackers which have been previously substantiated themselves. The activity tracker used in this research study was the Polar Active watch. This watch, to the researchers' knowledge, has not been validated. However, the two validated Polar activity trackers provide confidence of accuracy and precision in the Polar brand and its technology.

College students often experience more freedom in their lifestyle while in college than they have in previous years. This freedom can lead to changes in many areas of their lives, including food choices and physical activity habits. Previous research has examined energy intake and physical activity, separately as well as together in this population. While this previous research is important to understanding patterns, no research to our knowledge has examined energy intake after physical activity in the college student population. The current research study examined this situation in order to further the research base of college students and their corresponding energy intake and physical activity habits. This research will help create future nutrition interventions for college students. 


\section{REFERENCES}

2015-2020 Dietary Guidelines: Answers to Your Questions. (2016, January 5). Retrieved August 6, 2017, from https://www.choosemyplate.gov/2015-2020-dietary-guidelines-answersyour-questions

Adults - 2008 Physical Activity Guidelines - health.gov. (n.d.). Retrieved July 5, 2017, from https://health.gov/paguidelines/guidelines/adults.aspx

Allom, V., Mullan, B., Cowie, E., \& Hamilton, K. (2016). Physical activity and transitioning to college: The importance of intentions and habits. American Journal of Health Behavior, 40(2), 280-290. https://doi.org/10.5993/AJHB.40.2.13

Arnett, J. J. (2015). Emerging adulthood: the winding road from the late teens through the twenties. New York: Oxford University Press, [2015].

Barry, A. E., Whiteman, S., Piazza-Gardner, A. K., \& Jensen, A. C. (2013). Gender Differences in the Associations Among Body Mass Index, Weight Loss, Exercise, and Drinking Among College Students. Journal of American College Health, 61(7), 407. https://doi.org/10.1080/07448481.2013.823973

Boeselt, T., Spielmanns, M., Nell, C., Storre, J. H., Windisch, W., Magerhans, L., ... Koczulla, A. R. (2016). Validity and Usability of Physical Activity Monitoring in Patients with Chronic Obstructive Pulmonary Disease (COPD). PLoS ONE, 11(6), 1-11. https://doi.org/10.1371/journal.pone.0157229

Bryant, J. B., Darkes, J., \& Rahal, C. (2012). College Students' Compensatory Eating and Behaviors in Response to Alcohol Consumption. Journal of American College Health, 60(5), 350-356. https://doi.org/10.1080/07448481.2011.630702 
Ćatović, A., Dervisević, A., Lepara, O., Gorčević, S., \& Gorčević, J. (2014). Average saturated fatty acids daily intake in Sarajevo University students. Journal of Health Sciences, 4(3), 149.

CDC. (2016, September 27). Know Your Limit for Added Sugars. Retrieved November 29, 2017, from http://www.cdc.gov/nutrition/data-statistics/know-your-limit-for-addedsugars.html

Champagne, C. M., Han, H., Bajpeyi, S., Rood, J., Johnson, W. D., Lammi-Keefe, C. J., ... Bray, G. A. (2013). Research: Day-to-Day Variation in Food Intake and Energy Expenditure in Healthy Women: The Dietitian II Study. Journal of the Academy of Nutrition and Dietetics, 113, 1532-1538. https://doi.org/10.1016/j.jand.2013.07.001

Colby, S., Wenjun Zhou, Sowers, M. F., Shelnutt, K., Olfert, M. D., Morrell, J., ... Kattelmann, K. K. (2017). College Students' Health Behavior Clusters: Differences by Sex. American Journal of Health Behavior, 41(4), 378-389. https://doi.org/10.5993/AJHB.41.4.2

Deforche, B., Van Dyck, D., Deliens, T., \& De Bourdeaudhuij, I. (2015). Changes in weight, physical activity, sedentary behaviour and dietary intake during the transition to higher education: a prospective study. International Journal of Behavioral Nutrition \& Physical Activity, 12, 1 .

Durksen, A., Downs, S., Mollard, R., Forbes, L., Ball, G. D. C., \& McGavock, J. (2015). The Association Between Time Spent in Vigorous Physical Activity and Dietary Patterns in Adolescents: A Cross-Sectional Study. Journal of Physical Activity \& Health, 12(2), 208. 
El Ansari, W., Stock, C., \& Mikolajczyk, R. T. (2012). Relationships between food consumption and living arrangements among university students in four European countries -- A crosssectional study. Nutrition Journal, 11(1), 28-34. https://doi.org/10.1186/1475-2891-1128

Energy intake and expenditure - British Nutrition Foundation. (n.d.). Retrieved October 16, 2016, from https://www.nutrition.org.uk/nutritionscience/obesity-and-weightmanagement/energy-intake-and-expenditure.html?showall=1\&limitstart=

Fayet, F., Flood, V., Petocz, P., \& Samman, S. (2014). Avoidance of meat and poultry decreases intakes of omega-3 fatty acids, vitamin B12, selenium and zinc in young women. Journal of Human Nutrition \& Dietetics, 135-142. https://doi.org/10.1111/jhn.12092

Gorgulho, B., Marchioni, D. M. L., da Conceição, A. B., Steluti, J., Mussi, M. H., NagaiManelli, R., ... Fischer, F. M. (2012). Quality of diet of working college students. Work, $41,5806-5809$.

Gu, X., Zhang, T., \& Smith, K. (2015). Psychosocial Predictors of Female College Students' Motivational Responses: A Prospective Analysis. Perceptual And Motor Skills, 120(3), 700-713. https://doi.org/10.2466/06.PMS.120v19x0

Hebden, L., Chan, H. N., Louie, J. C., Rangan, A., \& Allman-Farinelli, M. (2015). You are what you choose to eat: factors influencing young adults' food selection behaviour. Journal of Human Nutrition \& Dietetics, 28(4), 401-408. https://doi.org/10.1111/jhn.12312

Hill, R. J., \& Davies, P. S. W. (2001). The validity of self-reported energy intake as determined using the doubly labelled water technique. British Journal of Nutrition, 85(4), 415-430. https://doi.org/10.1079/BJN2000281 
Jasti, S., Rubin, R., \& Doak, C. M. (2017). Sugar-sweetened Beverage Knowledge and Consumption in College Students.

Jones, E., Seki, L., Mostul, C., \& Coste, S. (2017). PREVALENCE AND USE OF FITNESS TRACKING DEVICES WITHIN A COLLEGE COMMUNITY. International Journal of Exercise Science: Conference Proceedings, 8(5). Retrieved from http://digitalcommons.wku.edu/ijesab/vol8/iss5/48

Kanitthika Kaewkannate, Soochan Kim, Kaewkannate, K., \& Kim, S. (2016). A comparison of wearable fitness devices. BMC Public Health, 16, 1-16. https://doi.org/10.1186/s12889016-3059-0

Kemmler, W., von Stengel, S., Kohl, M., \& Bauer, J. (2016). Impact of exercise changes on body composition during the college years--a five year randomized controlled study. $B M C$ Public Health, 16, 1-9. https://doi.org/10.1186/s12889-016-2692-y

Koulouri A, Tigbe WW, \& Lean MEJ. (2006). The effect of advice to walk 2000 extra steps daily on food intake. Journal of Human Nutrition \& Dietetics, 19(4), 263-266.

LaCaille, L. J. ., Dauner, K. N., Krambeer, R. J. ., \& Pedersen, J. (2011). Psychosocial and Environmental Determinants of Eating Behaviors, Physical Activity, and Weight Change Among College Students: A Qualitative Analysis. Journal of American College Health, 59(6), 531-538. https://doi.org/10.1080/07448481.2010.523855

Lewis, C. E., Jacobs, D. R., McCreath, H., Kiefe, C. I., Schreiner, P. J., Smith, D. E., \& Williams, O. D. (2009). Weight Gain Continues in the 1990s: 10-year Trends in Weight and Overweight from the CARDIA Study. American Journal of Epidemiology, 151(12), 1172. 
Martinez, Y. T. S., Harmon, B. E., Nigg, C. R., Bantum, E. O., \& Strayhorn, S. (2016). Diet and Physical Activity Intervention Strategies for College Students. Health Behavior \& Policy Review, 3(4), 336.

Mihalopoulos, N. L., Auinger, P., \& Klein, J. D. (2008). The Freshman 15: Is it Real? Journal of American College Health, 56(5), 531.

Morrell, J. S., Lofgren, I. E., Burke, J. D., \& Reilly, R. A. (2012). Metabolic Syndrome, Obesity, and Related Risk Factors Among College Men and Women. Journal of American College Health, 60(1), 82-89. https://doi.org/10.1080/07448481.2011.582208

Musselman, J. R. B., \& Rutledge, P. C. (2010). The incongruous alcohol-activity association: Physical activity and alcohol consumption in college students. Psychology of Sport \& Exercise, 11, 609-618. https://doi.org/10.1016/j.psychsport.2010.07.005

Năsui, B., \& Popescu, C. (2014). The assessment of the physical activity of Romanian university students in relation to nutritional status and academic performance. Estimarea Activităţii Fizice La Un Lot de Studenţi Din România În Relaţie Cu Starea de Nutriţie Și Performanţa Universitară., 15(2), 107-111.

Obesity Action Coalition » Empty Calories: Do they add up? (n.d.). Retrieved October 16, 2016, from http://www.obesityaction.org/educational-resources/resource-articles-2/generalarticles/empty-calories-do-they-add-up

O’leary, F., Hattersley, L., King, L., \& Allman-Farinelli, M. (2012). Sugary drink consumption behaviours among young adults at university. Nutrition \& Dietetics, 69(2), 119-123.

Physical Activity Basics | Physical Activity | CDC. (2017, July 5). Retrieved February 11, 2017, from https://www.cdc.gov/physicalactivity/basics/index.htm 
Quick, V. M., \& Byrd-Bredbenner, C. (2013). Disturbed eating behaviours and associated psychographic characteristics of college students. Journal of Human Nutrition \& Dietetics, 26, 53.

Scarapicchia, T. M. F., Sabiston, C. M., \& Faulkner, G. (2015). Exploring the prevalence and correlates of meeting health behaviour guidelines among university students. Canadian Journal Of Public Health = Revue Canadienne De Sante Publique, 106(3), e109-e114. https://doi.org/10.17269/cjph.106.4784

Seward, M. W., Block, J. P., \& Chatterjee, A. (2016). A Traffic-Light Label Intervention and Dietary Choices in College Cafeterias. American Journal of Public Health, 106(10), 1808-1814. https://doi.org/10.2105/AJPH.2016.303301

Smith-Jackson, T., \& Reel, J. J. (2012). Freshmen women and the "Freshman 15": perspectives on prevalence and causes of college weight gain. Journal Of American College Health: J Of ACH, 60(1), 14-20. https://doi.org/10.1080/07448481.2011.555931

Strohacker, K., Galárraga, O., Emerson, J., Fricchione, S. R., Lohse, M., \& Williams, D. M. (2015). Impact of Small Monetary Incentives on Exercise in University Students. American Journal of Health Behavior, 39(6), 779-785. https://doi.org/10.5993/AJHB.39.6.5

Subar, A. F., Freedman, L. S., Tooze, J. A., Kirkpatrick, S. I., Boushey, C., Neuhouser, M. L., ... Krebs-Smith, S. M. (2015). Addressing Current Criticism Regarding the Value of SelfReport Dietary Data. The Journal of Nutrition, 145(12), 2639-2645. https://doi.org/10.3945/jn.115.219634 
Sundblad, G. B., Jansson, A., Saartok, T., Renström, P., \& Engström, L.-M. (2008). Research papers: Self-rated pain and perceived health in relation to stress and physical activity among school-students: A 3-year follow-up. Pain, 136, 239-249. https://doi.org/10.1016/j.pain.2007.06.032

UCLA Nutrition Education. (n.d.). Retrieved November 12, 2016, from http://apps.medsch.ucla.edu/nutrition/dietassess.htm

Van Remoortel, H., Giavedoni, S., Raste, Y., Burtin, C., Louvaris, Z., Gimeno-Santos, E., ... Troosters, T. (2012). Validity of activity monitors in health and chronic disease: a systematic review. International Journal of Behavioral Nutrition \& Physical Activity, 9, 84-86. https://doi.org/10.1186/1479-5868-9-84

Warburton, D. E. R., Charlesworth, S., Ivey, A., Nettlefold, L., \& Bredin, S. S. D. (2010). A systematic review of the evidence for Canada's Physical Activity Guidelines for Adults. International Journal of Behavioral Nutrition \& Physical Activity, 7, 39-258. https://doi.org/10.1186/1479-5868-7-39

Waxman, A. (n.d.). The WHO Global Strategy on Diet, Physical Activity and Health: The controversy on sugar. Development, 47(2), 75-82. https://doi.org/10.1057/palgrave.dev.1100032

What Is Physical Activity? - NHLBI, NIH. (n.d.). Retrieved October 16, 2016, from https://www.nhlbi.nih.gov/health/health-topics/topics/phys

Yahia, N., Brown, C. A., Rapley, M., \& Chung, M. (2016). Level of nutrition knowledge and its association with fat consumption among... 
Zagorsky, J. L., \& Smith, P. K. (2011). The Freshman 15: A Critical Time for Obesity Intervention or Media Myth? Social Science Quarterly, 92, 1389-1407. https://doi.org/10.1111/\%28ISSN\%291540-6237/issues 


\section{APPENDIX A: DIETARY RECALL AND ACTIVITY LOG INSTRUCTIONS}

\section{KNR 113 Dietary Recall and Activity Log Instructions}

Dietary Recall:

You will be completing your seven-day dietary recall and activity log during the same seven days you wear the Polar activity tracker watch.

Each of the seven days of dietary recall and activity log should be filled out on a sheet of paper provided for you. You should have seven sheets of paper total, one sheet of paper for each day. Each sheet is double-sided.

On Day 1, for example, the front of the sheet has space for food and beverages and any physical activity you participate in. If you need more space to record your food and beverages, you may use the back of the sheet. For Day 2, you will move on to the second sheet of paper, titled "Day 2", and so on for all seven days.

Please be as specific as possible when filling out the log. Try to fill out the log throughout the day so you don't forget any food or drink you consume. When filling in the food or beverage consumed, please be very detailed. If you ate cereal and milk for breakfast, please write down exactly what type of cereal you ate (ex: Fruit Loops, Kashi GOLEAN Honey Almond Flax Crunch Cereal,

Cinnamon Toast Crunch, etc.). If you ate your cereal with milk, please write down what kind of milk you used (skim milk, $2 \%$ milk, almond milk, etc.). The more specific and detailed you can be, the better!

For the "Brand" column, please write in the brand of the food or beverage consumed (ex: Kellogg, Kashi, etc.). If the food does not have a brand, you can leave this space blank.

In the "Preparation Method" column, please write how the food was prepared. Was it homemade? If so, was it boiled, baked, fried, etc.? Was it from a restaurant? Which one? (ex: Olive Garden, Avanti's, etc.).

For the "Amount" column, please be as exact as possible when recording the amount of food or beverage consumed. If possible, measure the amount of food (cereal, for example) you want to eat in a measuring cup before placing it in the bowl, and do the same for anything that you want to add to the food (milk, for example). If you do not have access to measuring cups, use your best guess. 


\section{Activity Log:}

Only record intentional physical activity. If you're simply walking from your dorm to class or the cafeteria, do not record that. Record activity such as going to the gym, playing pick-up soccer, or going for a run or a walk around town. Please also note the time of day you participated in the physical activity and the approximate duration.

The activity log does not need to be as detailed as the dietary recall because you will be wearing the Polar activity tracker watches during this time and we will be able to get more detail about your physical activity levels from these. 
APPENDIX B: DIETARY RECALL AND ACTIVITY LOG TEMPLATE

\begin{tabular}{|l|l|l|l|l|l|}
\hline Date & Time & $\begin{array}{c}\text { Food/Reverage } \\
\text { Consumed }\end{array}$ & Brand & $\begin{array}{c}\text { Preparation } \\
\text { Method }\end{array}$ & $\begin{array}{c}\text { Amount } \\
\text { (ex: } 1 / 2 \text { cup })\end{array}$ \\
\hline & & & & & \\
\hline & & & & & \\
\hline & & & & & \\
\hline & & & & & \\
\hline & & & & & \\
\hline & & & & & \\
\hline & & & & & \\
\hline & & & & & \\
\hline & & & & & \\
\hline & & & & & \\
\hline & & & & & \\
\hline & & & & & \\
\hline & & & & & \\
\hline & & & & & \\
\hline & & & & & \\
\hline
\end{tabular}

